Research Article

\title{
Comparison of Cooperation Modes in a Two-Period Closed-Loop Supply Chain System considering Green Manufacturing
}

\author{
Chunmei Ma \\ School of Economics and Management, Chongqing Industry Polytechnic College, 1000 Taoyuan Road, Yu Bei District, \\ Chongqing 401120, China \\ Correspondence should be addressed to Chunmei Ma; macm@cqipc.edu.cn
}

Received 5 February 2020; Revised 20 March 2020; Accepted 13 April 2020; Published 22 May 2020

Academic Editor: Francesco Zammori

Copyright (c) 2020 Chunmei Ma. This is an open access article distributed under the Creative Commons Attribution License, which permits unrestricted use, distribution, and reproduction in any medium, provided the original work is properly cited.

In order to improve the efficiency of collection and green manufacturing level in a closed-loop supply chain (CLSC) system, the manufacturer invests green manufacturing efforts in product design and production process and intends to cooperate with other CLSC members to achieve excellent performance. In a two-period CLSC system consisting of one manufacturer, one retailer, and one third-service provider, a game-theoretical approach is adopted to compare the optimal decisions and profits of the three green manufacturing cooperation modes, namely, the manufacturer cooperates with the retailer and third-service provider, respectively, and the noncooperation mode is a benchmark. Moreover, the impact of different cooperation modes on CLSC decision-making is analyzed as well. The results indicate that the influence of difference among cooperation modes on CLSC decision is significant, and cooperation is always better than noncooperation. From the perspective of consumers as well as recycling and profit, although the collection rate of used products is not the highest when the manufacturer cooperates with the retailer, the price of product is the lowest and the green property of product is the most obvious; thus, this is regarded as the suitable cooperation mode after a comprehensive analysis. Besides, a coordination mechanism is designed to solve the inefficiency caused by double marginalization. Finally, numerical examples are presented to intuitively observe the relationships between decisions and profits and the impact of different parameters on them in the three modes, and some management inspirations are proposed ultimately.

\section{Introduction}

The development of technology contributes greatly to the progress of human society; consumers' lifestyle has been changed due to a large number of high-tech commodities, such as automobiles, household appliances, computers, and mobile phones. Although these products will bring convenience and diversity to consumers' various activities, they also consume a lot of resources during the process of production. Therefore, if the products cannot be fully reused and processed properly after being scrapped, it will cause serious environmental pollution and waste of resources [1]. Taking the automotive industry as an example, the total sales volume of the world's major auto markets was approximately 67.939 million units in 2018, which implies an increase in the number of scrapped automobiles. The components in scrapped automobiles contain hazardous substances such as plumbum, mercury, brominated flame retardant, and polyvinyl chloride plastics. However, the abandoned automobiles are not without merit; they can be turned from waste into treasure if rational utilization is implemented. For example, steel, plastic, rubber, nonferrous metals, and other resources present in scrapped automobiles are extremely valuable. Environmental and resource issues have also received widespread attention from governments and societies around the world. Therefore, some manufacturing enterprises actively implement the Extend Producer Responsibility (EPR) and part of the governments take EPR into consideration when formulating policies [2-5], such as Waste Electrical and Electronic Equipment Directive of European Commission, Specified Household Appliances Recycling Law of Japan, Waste Vehicle Treatment Regulations of Germany, and Extended Producer Responsibility System Implementation Plan of China $[1,6]$. The closed-loop supply chain (CLSC), which was proposed first in 2003 and has received extensive attention from the 
academic community due to both forward and reverse supply chain management, is included in it.

Because of the sustainable development requirements of regulations and market and the enterprises' aspiration of long-term development, as well as the other reasons, some enterprises have implemented CLSC management and proved that it can bring economic and environmental benefits. For instance, Volkswagen saves $70 \%$ in cost by reusing recycled car engines and other components. Interface Inc. chooses to lease carpets to carry out CLSC management to obtain the residual value of those products [7]. From 2003 to 2015, Hewlett-Packard reused 43.8 million computer parts and used more than 80,000 tons of recycled plastic to produce new ink cartridges and toner cartridges, which reduced greenhouse gas emissions and costs. However, recycling efficiency cannot be improved simply by collecting used products and reusing them, unless the products are designed with ease of remanufacturability and recyclability [8], which requires manufacturers to carry out green manufacturing, such as selecting raw materials that are effortless to recycle and optimizing production processes [9]. Besides, the positive impact of green innovation in product design on remanufacturing efficiency is very significant [10]. As everyone knows, green manufacturing innovation is a huge challenge for many enterprises, thus innovation should not be confined to a single enterprise; it is also necessary to seek for external cooperation to improve the efficiency of green manufacturing [11, 12]. Simultaneously, it is also important to choose a suitable partner, which can complement the scarce knowledge and resources [13] and improve the ability of green manufacturing. It is obvious that, in the context of advocating resource conservation and green manufacturing innovation, a comprehensive research on green manufacturing innovation and cooperation modes between members of the supply chain can enrich the theoretical study in the field of CLSC and provide suggestions of decision-making for enterprises and government. Therefore, this paper for the first time explores the abovementioned issues by establishing a dynamic two-period CLSC model which involves a manufacturer, a retailer, and a third-service provider, taking the manufacturer's green manufacturing innovation into consideration as well. More specifically,

(1) In a two-period CLSC system, what are the optimal green manufacturing levels, collection rates, pricing decisions, and profits when the manufacturer collaborates with different supply chain members?

(2) What is the impact of cooperating with different members (i.e., different cooperation modes) on decision-making?

(3) Who is the best partner for the manufacturer (i.e., which cooperation mode is optimal)?

(4) How to solve inefficiencies in decentralized CLSC?

Hence, the contributions of this research to academics are reflected in the following aspects. Firstly, the influence of different cooperation modes on optimal CLSC strategies and profits is investigated when the manufacturer's green manufacturing innovation and CLSC dynamics are considered synchronously. Secondly, the optimal cooperation mode is analyzed from the point of view of consumers, green manufacturing, recycling, and CLSC system; thus, this paper is valuable in both theory and practice. The rest of this paper is structured as follows. Section 2 reviews the related literature. Section 3 gives the description of problem, definition of symbols, and basic assumptions. Section 4 presents game theoretic models of different cooperation modes and equilibrium results. Section 5 analyzes the equilibrium results in Section 4 and managerial insights are obtained. Moreover, a coordination mechanism is designed to improve the efficiency of the CLSC system. Section 6 shows the numerical examples of the propositions mentioned in Section 5 and additional implications are presented. Finally, we conclude the study in Section 7.

\section{Literature Review}

In this section, the related studies are reviewed to set forth the necessity of this research. We mainly focus on three issues which are shown in three sections. In Section 2.1, we address the literature on CLSC. Section 2.2 illustrates the literature related to green manufacturing innovation. Section 2.3 reviews research on cooperation in the supply chain.

2.1. CLSC. Due to the environmentally friendly nature of CLSC and the differences compared to the traditional supply chain, scholars have shown a high research enthusiasm for CLSC. The literature on CLSC mainly focuses on three directions, namely, the channel selection of used-product collection, analysis of optimal decisions, and CLSC coordination. More specifically, Savaskan et al. [14] introduce three channels for the manufacturer to collect the used products, namely, the manufacturer, retailer, and the third party is responsible for collection activity, respectively. A game-theoretical approach is adopted to analyze those three channels under the scenario that the manufacturer is the Stackelberg leader, and they find that when the retailer is recycler, the operational efficiency is the highest. Their study is so classical that many researchers have expanded on it and referenced it, such as Savaskan and Van Wassenhove [15] study the structure of collecting channel in the case of considering competition among retailers. Huang et al. [16] shift the focus of research to dual collection channel, which encompasses a retailer and a third party, competing with each other in collecting used products. Meanwhile, by comparing with models of Savaskan et al. [14], the conditions of constructing dual collection channel are obtained. Besides, both Hong et al. [17] and Liu et al. [18] suppose three optional dual collection channels for the manufacturer, more specifically, the manufacturer and retailer collecting used products simultaneously, the manufacturer outsourcing the collection activity to a retailer and third party, and the manufacturer and third party jointly managing the recycling business. The results of their studies indicate that the dual collection channel consisting of the manufacturer and retailer is superior to the other two obviously. 
Moreover, other researchers pay attention to the optimal decisions of CLSC members and consider more practical factors, for example, Huang [19] investigates three mathematical models of CLSC, in which the used products are collected through trade-in strategy, and the competition among retailers is also considered. Gao et al. [20] take the collection effort and sales effort into consideration to explore the impact of different channel power structures on CLSC's decision-making. Gu et al. [21] investigate the particularity of electric vehicle battery CLSC and analyze the optimal pricing decisions of the manufacturer and remanufacturer.

On account of the existence of dual marginalization in decentralized CLSC, some researchers propose coordination mechanisms to solve this issue. In order to coordinate the CLSC, Zhang et al. [22] design two contracts for CLSC with symmetric information and asymmetric information, respectively, and game theory is adopted to obtain the most suitable contract. Hasanov et al. [23] study the coordination among order quantities and shipments quantities in a fourlevel CLSC by establishing two mixed-integer nonlinear programming mathematical models. He et al. [24] compare contract and authorization mechanism to affirm which one can improve the recovery efficiency in a decentralized CLSC, and their results indicate that the contract mechanism is superior to the other one.

Apparently, the aforesaid literature is confined to single period CLSC, which implies that the products sold can be collected in the same period. However, the products such as household appliances, computers, and automobiles have a certain life cycle; thus, they cannot be recycled immediately. Therefore, a part of researchers have investigated the twoperiod CLSC, for instance, Giovanni and Zaccour [25] establish a two-period dynamic game model of CLSC to analyze the conditions of outsourcing the collection business. Analogously, Genc and Giovanni [26] develop a two-period Stackelberg game that considers the profit seeking of consumers and retail competition to find the best recycler. Wang et al. [1] study the influence of reward-penalty mechanism on decisions and profitability of CLSC by developing a two-period game model. $\mathrm{Xu}$ and Wang [27] develop a two-period model where the consumer's lowcarbon and remanufactured preference are considered to investigate the decisions and profit distribution of CLSC. However, the content related to manufacturers' behavior of green manufacturing innovation is not included in the abovementioned studies. As stated in Section 1, if the manufacturer not only recycles waste product but also carry out green manufacturing innovation in the production process, then better environmental benefits can be obtained. Therefore, it is necessary to consider this in the study.

2.2. Green Manufacturing Innovation. As mentioned in the previous section, relying solely on recycling cannot improve the operational efficiency of CLSC, it is necessary for the manufacturer to implement green manufacturing innovation during the design and production process. Reimann et al. [8] study the relationship between remanufacturing and the chance to reduce the variable remanufacturing cost via process innovation and point out that the optimal strategy of managing process innovation in the forward supply chain cannot be applied directly to CLSC. Genc and Giovanni [26] adopt a game-theoretic approach to construct models to investigate the influence of innovation-led lean programs in a CLSC; their results show that these programs have both strategic and process innovation effect, which are conducive to manufacturer and sustainability. Arfi et al. [9] analyze the impact of internal and external knowledge sharing on green innovation and organization performance via empirical research. Cherrafi et al. [28] adopt Structural Equation Modeling to analyze the data of 374 manufacturing enterprises; the findings indicate that the relationship between lean, process, and green innovation practices is synergistic, and it is important to improve green supply chain performance. Liu et al. [10] explore the impact of product design on operational efficiency of a two-echelon CLSC; the results show that remanufacturing cannot ensure the profitability of CLSC members, whereas the adjustment of product design strategies can remedy this problem. The abovementioned literature mainly focuses on green manufacturing innovation of CLSC from a macroperspective. While more detailed exploration are carried out from a micropoint of view by some scholars, such as Albino et al. [29, 30], Messeni Petruzzelli et al. [31], and Ardito et al. $[32,33]$.

We can find that the topic of the aforementioned literature is the innovation behaviors of enterprises, and the cooperation between enterprises in the supply chain is not considered. In the context of the supply chain management, it has been very difficult for companies to achieve competitiveness through single-handedness, due to lack of capital and technology. Consequently, in the CLSC management, research on the cooperation mode between enterprises is also one of the important issues.

2.3. Cooperation. Because of the difficulty of green manufacturing innovation for most firms, thus cooperation or alliance is an important way to improve performance. Dai et al. [11] use a game-theoretical approach to compare the cases of cartelization, cost-sharing contract, and noncooperation in a green supply chain, in which both the upstream and downstream firms tend to establish Research and Development collaborations; they discovered that cooperation always benefits consumers and environment. Zhang et al. [34] build an evolutionary game model to investigate the modes of technology diffusion and the impact of low-carbon policy on technology diffusion in the alliance. Based on the analysis of a large amount of data, Doblinger et al. [35] emphasize the crucial role of government to be a partner in the technology development alliance, which will facilitate the innovation process. Elia et al. [13] point out that the impact of cultural diversity among an alliance's partners is not always negative, such as in an explorative alliance, the influence of cultural diversity is positive. These articles only study the issue related to cooperation between enterprises in the forward supply chain, while how enterprises in CLSC should cooperate and which cooperation mode is most 
beneficial to green manufacturing innovation have not been mentioned.

According to the existing literature, we find that the directions such as CLSC, two-period CLSC, green manufacturing innovation, and cooperation are all involved, and these studies lay the foundation for the research of this paper. However, a comprehensive study which combines the two-period CLSC and the cooperation of green manufacturing innovation has not been given sufficient attention and relevant research is scarce. In contrast to the existing literature, this paper investigates the optimal decisions of a two-period CLSC, in which the green manufacturing innovation of the manufacturer is considered in three cooperation modes. Specifically, the research content of our study includes not only the two-period CLSC and green manufacturing innovation of the manufacturer but also the cooperation mode between enterprises. The scope of this paper is wider and more realistic, and the results of the research also have higher theoretical and practical significance. In addition, we also discuss the impact of different cooperation modes on CLSC members' decision-making and the optimal partner is proposed via comparisons among the three cooperation modes. A coordination mechanism is proposed for the optimal mode.

\section{Scenarios and Assumptions}

3.1. Problem Description. Considering the new products sold today cannot be recycled immediately, these products will be collected and remanufactured only in the future; therefore, dynamic modeling appears the most appropriate setting [25]. This paper investigates a two-period CLSC consisting of a manufacturer, a retailer, and a third-service provider. As shown in Figure 1, the manufacturer does wholesale business with a retailer to sell its products at a wholesale price $w_{i}, i$ indicates the period index, and $i=1,2$; then, the retailer gains profits by selling products to consumers at a retail price $p_{i}$, and the third-service provider is exclusively responsible for the collection activity. In order to implement its social responsibility and attract green consumers, the manufacturer invests in green activities such as adopts resource-saving production technologies and equipment, designs product towards environmental protection, and reduces the carbon emissions of each product. In this two-period CLSC, the relationship between the manufacturer and other agents is described as a Stackelberg game, where the manufacturer acts as the leader and the retailer and third-service provider as the followers. More specifically, the manufacturer decides its wholesale price and green manufacturing efforts, and then, the retailer and third-service provider determine their retail price and collection efforts, respectively. Moreover, the manufacturer has a tendency to cooperate with other members to improve the green manufacturing efficiency, the collection efficiency of end-of-use products, and achieve the goal of increasing the performance of the entire CLSC system ultimately.

For the purpose of obtaining the optimal wholesale price and retail price and optimizing the green manufacturing as well as collection efficiency in two periods, the manufacturer can confirm who is a suitable partner simultaneously. Therefore, we propose the Stackelberg game.

3.2. Definition of Symbols. Based on the abovementioned description, some symbols are included in the mathematical models to construct Stackelberg game models. The definitions of symbols are as follows:

$a$ is market potential

$b$ is consumer's sensitivity to retail price

$p_{i}$ is retail price of unit product in period $i$, retailer's decision variable

$\theta_{i}$ is green manufacturing innovation level of unit product in period $i$, manufacturer's decision variable

$w_{i}$ is wholesale price of unit product in period $i$, manufacturer's decision variable

$\phi$ is consumer's sensitivity to green products

$\zeta$ is discount factor of second-period profit, $0<\zeta<1$

$\lambda$ is collection rate of end-of-use products, third-service provider's decision variable, $0<\lambda<1$

$c_{m}$ is unit cost of producing product from brand-new materials

$c_{r}$ is unit cost of producing product from recycled materials

$\Delta$ is saving unit cost from using recycled materials, $\Delta=c_{m}-c_{r}$

$c_{f}$ is unit transfer price of used products from the thirdservice provider

$r$ is average recycling price of used products from the consumers

$I$ is investment parameter of green manufacturing innovation

$K$ is investment parameter of used-product collection

Apparently, the subscript $i$ represents the period index, $i=1,2$.

3.3. Basic Assumptions. In order to achieve the purpose of this research and establish the mathematical models, some basic assumptions based on previous literature (e.g., [14, 25]) should be proposed:

(1) There is no distinction between remanufactured products and new products, and they can be sold in the same market at the same price.

(2) The CLSC members are risk-neutral, and all information is symmetrical.

(3) The third-service provider's investment in collection activity in period 2 is assumed to be an increasing convex function $C(\lambda)$ and $K$ is assumed to be sufficiently large to ensure $0<\lambda<1$; this implies that remanufacturing is so costly that all the used products being collected is impracticable. This kind 


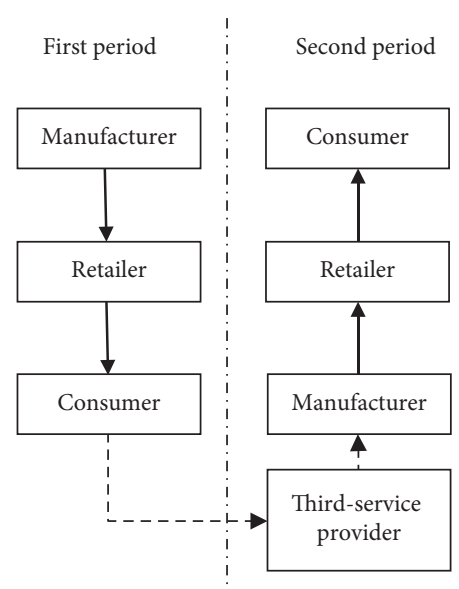

No-cooperation(NC)

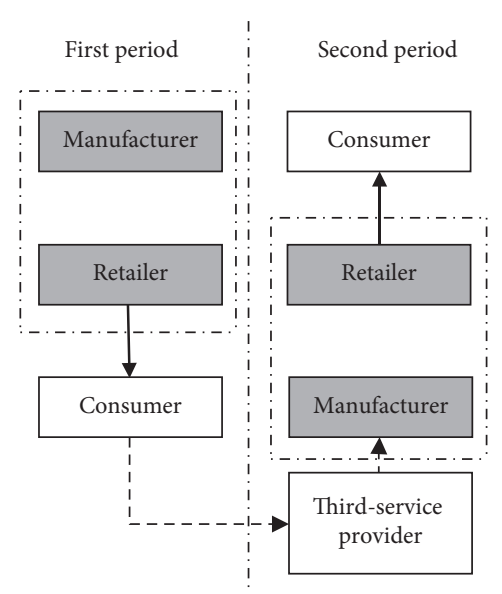

Cooperation of manufacturer and retailer (MR-C)

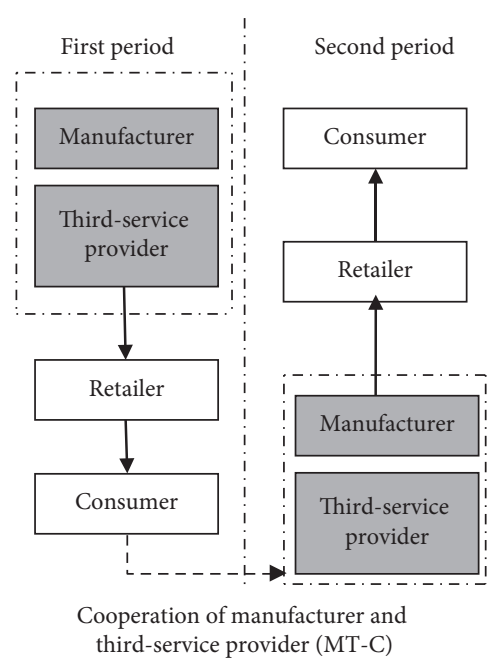

$\longrightarrow$ Forward logistics

$\rightarrow$ Reverse logistics

FIGURE 1: The structure of two-period CLSC under three cooperation modes.

of cost structure and corresponding description is similar to Savaskan et al. [14], which is given by

$$
C(\lambda)=K \lambda^{2} \text {. }
$$

Analogously, manufacturer's cost of green manufacturing innovation is given by an increasing convex function $\mathrm{C}\left(\theta_{i}\right)$, and we also suppose that $I$ is sufficiently large to describe the difficulty of green manufacturing innovation; such a cost function structure is commonly used in relevant literature [36] and is given by

$$
C\left(\theta_{i}\right)=I \theta_{i}^{2}
$$

(4) Manufacturing products with new materials is more costly than returned materials from used products, that is, $\Delta=c_{m}-c_{r}>0$. Simultaneously, only when $\Delta-c_{f}>0$ is satisfied, we can ensure that the manufacturer has the motivation to remanufacture. Moreover, $c_{f}$ is composed of all the reverse flow management costs such as collection, transportation, classification, inspection, and other activities. It is well known that only part of the collected products can be used for remanufacturing; however, in order to analyze the optimal strategies of supply chain members, without loss of generality, we suppose that all returned products can be remanufactured successfully [20].

(5) With the continuous development of the economy, except the basic function of products, consumers' attention to the green level, for example, energy efficiency of products, is gradually increasing. Thus, in order to attract more green consumers, the manufacturer will improve the green manufacturing efficiency. Therefore, we assume that the market demand $q$ is a linear function of the retail price and green manufacturing innovation level, and $q$ is equal in two periods, which is defined as

$$
q\left(p_{i}, \theta_{i}\right)=a-b p_{i}+\phi \theta_{i} .
$$

Obviously, the market demand is a decreasing function of retail price and an increasing function of green manufacturing innovation level [27].

(6) In this paper, we suppose that there are three cooperation modes between supply chain members. More specifically, they are noncooperation mode (NC), the manufacturer cooperates with the retailer (MR-C) and the third-service provider (MT-C), respectively. Because the purpose of our study is to determine the optimal cooperation mode and the best partner, therefore, this paper is different from the research of Capaldo and Messeni Petruzzelli [37, 38] and Ardito et al. [39], which mainly focus on the impact of proximity dimensions between partners on cooperation dynamics. In order to simplify the mathematical model and achieve the main research purpose, only the case where the tightness of cooperation is the highest is taken into consideration in this paper; other scenarios such as loose cooperation and closer cooperation can be negligible.

\section{Models of CLSC under Different Cooperation Modes}

4.1. Noncooperation Mode (Model NC). In this scenario, all the CLSC members are profit seeking and make decisions separately. Therefore, the profit functions of three players can be formulated as 


$$
\begin{aligned}
\Pi_{\mathrm{M}}^{\mathrm{NC}}= & \left(w_{1}^{\mathrm{NC}}-c_{m}\right)\left(a-b p_{1}^{\mathrm{NC}}+\phi \theta_{1}^{\mathrm{NC}}\right)-I\left(\theta_{1}^{\mathrm{NC}}\right)^{2} \\
& +\zeta\left[\left(w_{2}^{\mathrm{NC}}-c_{m}\right)\left(a-b p_{2}^{\mathrm{NC}}+\phi \theta_{2}^{\mathrm{NC}}\right)+\lambda^{\mathrm{NC}}\left(\Delta-c_{f}\right)\left(a-b p_{1}^{\mathrm{NC}}+\phi \theta_{1}^{\mathrm{NC}}\right)-I\left(\theta_{1}^{\mathrm{NC}}\right)^{2}\right], \\
\Pi_{\mathrm{R}}^{\mathrm{NC}}= & \left(p_{1}^{\mathrm{NC}}-w_{1}^{\mathrm{NC}}\right)\left(a-b p_{1}^{\mathrm{NC}}+\phi \theta_{1}^{\mathrm{NC}}\right)+\zeta\left(p_{2}^{\mathrm{NC}}-w_{2}^{\mathrm{NC}}\right)^{2}\left(a-b p_{2}^{\mathrm{NC}}+\phi \theta_{2}^{\mathrm{NC}}\right), \\
\Pi_{\mathrm{T}}^{\mathrm{NC}}= & \zeta\left[\lambda^{\mathrm{NC}}\left(c_{f}-r\right)\left(a-b p_{1}^{\mathrm{NC}}+\phi \theta_{1}^{\mathrm{NC}}\right)-K\left(\lambda^{\mathrm{NC}}\right)^{2}\right] .
\end{aligned}
$$

The equilibrium results in this mode will be superscripted by NC. Consequently, the manufacturer's objective function is as follows:

$$
\begin{aligned}
& \underset{w_{1}^{\mathrm{NC}}, \theta_{1}^{\mathrm{NC}}, w_{2}^{\mathrm{NC}}, \theta_{2}^{N C}}{\operatorname{MAX}} \Pi_{\mathrm{M}}^{\mathrm{NC}} \\
& \begin{array}{lll} 
& \operatorname{MAX} & \Pi_{\mathrm{R}}^{\mathrm{NC}} \\
\text { S.T. } & P_{1}^{\mathrm{NC}}, P_{2}^{\mathrm{NC}} & \\
& \operatorname{MAX}_{\lambda_{\mathrm{N}}^{\mathrm{NC}}}^{\mathrm{NC}}, & \Pi_{\mathrm{T}}^{\mathrm{NC}},
\end{array} \\
& \text { Subject to: } w_{i}^{\mathrm{NC}}, p_{i}^{\mathrm{NC}}, \theta_{i}^{\mathrm{NC}}>0,0<\lambda^{\mathrm{NC}}<1, a>b p_{i}^{\mathrm{NC}}, \quad i=1,2 \text {. }
\end{aligned}
$$

For the purpose of obtaining equilibrium decisions, we adopt backward induction in the calculation section, and the sequence is similar to Giovanni and Zaccour [25].
Proposition 1. Assuming an interior solution exists, the equilibrium strategies of CLSC members in noncooperation mode are given by

$$
\begin{aligned}
& w_{1}^{\mathrm{NC}}=\frac{4 I K\left(a+b c_{m}\right)-K c_{m} \phi^{2}-a B}{K A-b B} \\
& P_{1}^{\mathrm{NC}}=\frac{2 I K\left(3 a+b c_{m}\right)-K c_{m} \phi^{2}-a B}{K A-b B} \\
& \theta_{1}^{N C}=\frac{K \phi\left(a-b c_{m}\right)}{K A-b B}, \\
& q_{1}^{\mathrm{NC}}=\frac{2 I K b\left(a-b c_{m}\right)}{K A-b B}, \\
& \lambda^{\mathrm{NC}}=\frac{I b\left(c_{f}-r\right)\left(a-b c_{m}\right)}{K A-b B}, \\
& w_{2}^{\mathrm{NC}}=\frac{4 I b c_{m}+4 I a-c_{m} \phi^{2}}{A}, \\
& \theta_{2}^{\mathrm{NC}}=\frac{\phi\left(a-b c_{m}\right)}{A}, \\
& P_{2}^{\mathrm{NC}}=\frac{2 I b c_{m}+6 I a-c_{m} \phi^{2}}{A}, \\
& A
\end{aligned}
$$


where $A=8 I b-\phi^{2}$ and $B=2 I b \zeta\left(\Delta-c_{f}\right)\left(c_{f}-r\right)$

The corresponding equilibrium profits are as follows:

$$
\begin{aligned}
\Pi_{\mathrm{M}}^{\mathrm{NC}} & =\frac{I\left(a-b c_{m}\right)^{2}[K A(1+\zeta)-b \zeta B]}{A[K A-b B]}, \\
\Pi_{\mathrm{R}}^{\mathrm{NC}} & =\frac{4 I^{2} b\left(a-b c_{m}\right)^{2}\left[K^{2} A^{2}(1+\zeta)-2 K b \zeta B A+b^{2} \zeta B^{2}\right]}{A^{2}[K A-b B]^{2}}, \\
\Pi_{\mathrm{T}}^{\mathrm{NC}} & =\frac{I^{2} K b^{2} \zeta\left(a-b c_{m}\right)^{2}\left(c_{f}-r\right)^{2}}{[K A-b B]^{2}}, \\
\Pi_{\mathrm{S}}^{\mathrm{NC}} & =\frac{I\left(a-b c_{m}\right)^{2}\left[K^{2} A^{2}\left(12 I b-\phi^{2}\right)(1+\zeta)+b^{2} \zeta B^{2}\left(12 I b-\phi^{2}\right)-2 K b \zeta B A\left(12 I b-\phi^{2}\right)-I K b^{2} \zeta\left(c_{f}-r\right)\left(2 \Delta-3 c_{f}+r\right) A^{2}\right]}{A^{2}[K A-b B]^{2}} .
\end{aligned}
$$

For an interior solution, some conditions should be satisfied. We shall insure that the values of $w_{i}^{\mathrm{NC}}, p_{i}^{\mathrm{NC}}$, and $\theta_{i}^{\mathrm{NC}}$ are positive, and $0<\lambda^{\mathrm{NC}}<1, a>b p_{i}^{\mathrm{NC}}$, where $i=1,2$. This implies that $A>0, K A-b B>0$, and $K A>b B+$ $I b\left(c_{f}-r\right)\left(a-b c_{m}\right)$; more specifically, $K>\left(I b\left(c_{f}-r\right)(a-\right.$ $\left.\left.b c_{m}\right)+2 I b^{2} \zeta\left(\Delta-c_{f}\right)\left(c_{f}-r\right)\right) /\left(8 I b-\phi^{2}\right)$, and these conditions are supposed to hold.

4.2. Cooperation of Manufacturer and Retailer (Model MR-C). In the MR-C mode, a partnership is formed between the manufacturer and retailer; they determine their strategies jointly instead of making decisions separately, such as the retail price and the green manufacturing innovation level, and their common goal is to maximize the profit of the cooperative organization. Because of the cooperative relationship between the manufacturer and retailer, the wholesale price disappears reasonably in this scenario. Obviously, due to the dominant power of the manufacturer, the MR-C organization has sufficient ability to act as a Stackelberg leader and dominate the whole system, and third-service provider is the unique follower. Therefore, the profit function of MR-C organization is defined as

$$
\begin{aligned}
\Pi_{\mathrm{C}}^{\mathrm{MR}-\mathrm{C}}= & \left(p_{1}^{\mathrm{MR}-\mathrm{C}}-c_{m}\right)\left(a-b p_{1}^{\mathrm{MR}-\mathrm{C}}+\phi \theta_{1}^{\mathrm{MR}-\mathrm{C}}\right) \\
& -I\left(\theta_{1}^{\mathrm{MR}-\mathrm{C}}\right)^{2}+\varsigma\left[\left(p_{2}^{\mathrm{MR}-\mathrm{C}}-c_{m}\right)\right. \\
& \cdot\left(a-b p_{2}^{\mathrm{MR}-\mathrm{C}}+\phi \theta_{2}^{\mathrm{MR}-\mathrm{C}}\right)+\lambda^{\mathrm{MR}-\mathrm{C}}\left(\Delta-c_{f}\right) \\
& \left.\cdot\left(a-b p_{1}^{\mathrm{MR}-\mathrm{C}}+\phi \theta_{1}^{\mathrm{MR}-\mathrm{C}}\right)-I\left(\theta_{2}^{\mathrm{MR}-\mathrm{C}}\right)^{2}\right],
\end{aligned}
$$

and the profit function of the third-service provider in this scenario can be defined as

$$
\begin{aligned}
\Pi_{\mathrm{T}}^{\mathrm{MR}-\mathrm{C}}= & \varsigma\left[\lambda^{\mathrm{MR}-\mathrm{C}}\left(c_{f}-r\right)\left(a-b_{1}^{\mathrm{MR}-\mathrm{C}}+\phi \theta_{1}^{\mathrm{MR}-\mathrm{C}}\right)\right. \\
& \left.-K\left(\lambda^{\mathrm{MR}-\mathrm{C}}\right)^{2}\right] .
\end{aligned}
$$

Analogously, the equilibrium results in this mode will be superscripted by MR-C, and the MR-C organization's objective function is formulated as

$$
\begin{array}{lll}
\underset{p_{1}^{\mathrm{MR}-\mathrm{C}}, \theta_{1}^{\mathrm{MR}-\mathrm{C}}, p_{2}^{\mathrm{MR}-\mathrm{C}}, \theta_{2}^{\mathrm{MR}-\mathrm{C}}}{\mathrm{MAX}} & \Pi_{\mathrm{C}}^{\mathrm{MR}-\mathrm{C}} \\
\text { S.T. } & \underset{\lambda^{\mathrm{MR}-\mathrm{C}}}{\mathrm{MAX}} & \Pi_{\mathrm{T}}^{\mathrm{MR}-\mathrm{C}},
\end{array}
$$

Subject to $p_{i}^{\mathrm{MR}-\mathrm{C}}, \theta_{i}^{\mathrm{MR}-\mathrm{C}}>0,0<\lambda^{\mathrm{MR}-\mathrm{C}}<1$, and $a>b p_{i}^{\mathrm{MR}-\mathrm{C}}$, $i=1,2$

Again, we adopt backward induction to calculate the models and obtain equilibrium decisions and refer to the calculation steps of Giovanni and Zaccour [25].

Proposition 2. Assuming an interior solution, the equilibrium strategies of the cooperative organization and thirdservice provider when the manufacturer cooperates with the retailer are given by

$$
\begin{aligned}
p_{1}^{\mathrm{MR}-\mathrm{C}} & =\frac{2 I K\left(a+b c_{m}\right)-K c_{m} \phi^{2}-a B}{K Q-b B}, \\
\theta_{1}^{\mathrm{MR}-\mathrm{C}} & =\frac{K \phi\left(a-b c_{m}\right)}{K Q-b B}, \\
q_{1}^{\mathrm{MR}-\mathrm{C}} & =\frac{2 I K b\left(a-b c_{m}\right)}{K Q-b B}, \\
\lambda^{\mathrm{MR}-\mathrm{C}} & =\frac{I b\left(c_{f}-r\right)\left(a-b c_{m}\right)}{K Q-b B}, \\
p_{2}^{\mathrm{MR}-\mathrm{C}} & =\frac{2 I\left(a+b c_{m}\right)-c_{m} \phi^{2}}{Q}, \\
\theta_{2}^{\mathrm{MR}-\mathrm{C}} & =\frac{\phi\left(a-b c_{m}\right)}{Q}, \\
q_{2}^{\mathrm{MR}-\mathrm{C}} & =\frac{2 I b\left(a-b c_{m}\right)}{Q},
\end{aligned}
$$

where $Q=4 I b-\phi^{2}$ and $B=2 I b \zeta\left(\Delta-c_{f}\right)\left(c_{f}-r\right)$ 
The corresponding equilibrium profits are as follows:

$$
\begin{aligned}
\Pi_{\mathrm{C}}^{\mathrm{MR}-\mathrm{C}} & =\frac{I\left(a-b c_{m}\right)^{2}[K Q(1+\zeta)-b \zeta B]}{\mathrm{Q}[K Q-b B]}, \\
\Pi_{\mathrm{T}}^{\mathrm{MR}-\mathrm{C}} & =\frac{I^{2} K b^{2} \zeta\left(a-b c_{m}\right)^{2}\left(c_{f}-r\right)^{2}}{[K Q-b B]^{2}}, \\
\Pi_{\mathrm{S}}^{\mathrm{MR}-\mathrm{C}} & =\frac{I\left(a-b c_{m}\right)^{2}\left[K^{2} Q^{2}(1+\zeta)+b^{2} \zeta B^{2}-2 K b \zeta B Q-I K b^{2} \zeta\left(c_{f}-r\right)\left(2 \Delta-3 c_{f}+r\right) Q\right]}{Q[K Q-b B]^{2}} .
\end{aligned}
$$

Again, some conditions should be established to obtain an interior solution. Namely, $p_{i}^{\mathrm{MR}-\mathrm{C}}, \theta_{i}^{\mathrm{MR}-\mathrm{C}}>0$, $0<\lambda^{\mathrm{MR}-\mathrm{C}}<1$, and $a>b p_{i}^{\mathrm{MR}-\mathrm{C}}, i=1,2$, and the values of $Q$ and $K Q-b B$ are positive.

Furthermore, $K Q>b B+I b\left(c_{f}-r\right)\left(a-b c_{m}\right) \Leftrightarrow K>$ $\left(\left(I b\left(c_{f}-r\right)\left(a-b c_{m}\right)+2 I b^{2} \zeta\left(\Delta-c_{f}\right)\left(c_{f}-r\right)\right) /\left(4 I b-\phi^{2}\right)\right)$; we suppose these conditions to hold.

4.3. Cooperation of Manufacturer and Third-Service Provider (Model MT-C). It is obvious that the manufacturer chooses the third-service provider as its partner in this scenario. Therefore, they jointly determine the wholesale price, the green manufacturing innovation level, and the collection rate. Similar to the previous scenario, the transfer price does not exist and the cooperative organization is the Stackelberg leader and the retailer is the follower. Thus, the profit function of MT-C organization can be defined as

$$
\begin{aligned}
\Pi_{\mathrm{C}}^{\mathrm{MT}-\mathrm{C}}= & \left(w_{1}^{\mathrm{MT}-\mathrm{C}}-c_{m}\right)\left(a-b p_{1}^{\mathrm{MT}-\mathrm{C}}+\phi \theta_{1}^{\mathrm{MT}-\mathrm{C}}\right)-I\left(\theta_{1}^{\mathrm{MT}-\mathrm{C}}\right)^{2} \\
& +\zeta\left[\left(w_{2}^{\mathrm{MT}-\mathrm{C}}-c_{m}\right)\left(a-b p_{2}^{\mathrm{MT}-\mathrm{C}}+\phi \theta_{2}^{\mathrm{MT}-\mathrm{C}}\right)\right. \\
& +\lambda^{\mathrm{MT}-\mathrm{C}}(\Delta-r)\left(a-b p_{1}^{\mathrm{MT}-\mathrm{C}}+\phi \theta_{1}^{\mathrm{MT}-\mathrm{C}}\right) \\
& \left.-I\left(\theta_{1}^{\mathrm{MT}-\mathrm{C}}\right)^{2}-K\left(\lambda^{\mathrm{MT}-\mathrm{C}}\right)^{2}\right] .
\end{aligned}
$$

Simultaneously, the profit function of the retailer in this scenario is defined as

$$
\begin{aligned}
\Pi_{\mathrm{R}}^{\mathrm{MT}-\mathrm{C}}= & \left(p_{1}^{\mathrm{MT}-\mathrm{C}}-w_{1}^{\mathrm{MT}-\mathrm{C}}\right)\left(a-b p_{1}^{\mathrm{MT}-\mathrm{C}}+\phi \theta_{1}^{\mathrm{MT}-\mathrm{C}}\right) \\
& +\zeta\left(p_{2}^{\mathrm{MT}-\mathrm{C}}-w_{2}^{\mathrm{MT}-\mathrm{C}}\right)\left(a-b p_{2}^{\mathrm{MT}-\mathrm{C}}+\phi \theta_{2}^{\mathrm{MT}-\mathrm{C}}\right)
\end{aligned}
$$

Similarly, the equilibrium results in this scenario will be superscripted by MT-C, and the MT-C organization's objective function is defined as

$$
\begin{array}{r}
\underset{w_{1}^{\mathrm{MT}-\mathrm{C}}, \theta_{1}^{\mathrm{MT}-\mathrm{C}}, w_{2}^{\mathrm{MT}-\mathrm{C}}, \theta_{2}^{\mathrm{MT}-\mathrm{C}}, \lambda^{\mathrm{MT}-\mathrm{C}}}{\mathrm{MAX}} \Pi_{\mathrm{C}}^{\mathrm{MT}-\mathrm{C}} \\
\text { S.T. } \underset{p_{1}^{\mathrm{MT}-\mathrm{C}}, p_{2}^{\mathrm{MT}-\mathrm{C}}}{\mathrm{MAX}} \Pi_{\mathrm{R}}^{\mathrm{MT}-\mathrm{C}},
\end{array}
$$

Subject to $w_{i}^{\mathrm{MT}-\mathrm{C}}, p_{i}^{\mathrm{MT}-\mathrm{C}}, \theta_{i}^{\mathrm{MT}-\mathrm{C}}>0,0<\lambda^{\mathrm{MT}-\mathrm{C}}<1$, and $a>b p_{i}^{\mathrm{MT}-\mathrm{C}}, i=1,2$.

In order to obtain equilibrium decisions, we adopt the calculation method which is similar to the previous scenarios.

Proposition 3. Assuming an interior solution, the equilibrium strategies of the cooperative organization and retailer when the manufacturer cooperates with the third-service provider are as follows:

$$
\begin{aligned}
& w_{1}^{\mathrm{MT}-\mathrm{C}}=\frac{4 I K\left(a+b c_{m}\right)-K c_{m} \phi^{2}-a R}{K A-b R}, \\
& p_{1}^{\mathrm{MT}-\mathrm{C}}=\frac{2 I K\left(3 a+b c_{m}\right)-K c_{m} \phi^{2}-a R}{K A-b R}, \\
& \theta_{1}^{\mathrm{MT}-\mathrm{C}}=\frac{K \phi\left(a-b c_{m}\right)}{K A-b R} \\
& \lambda^{\mathrm{MT}-\mathrm{C}}=\frac{I b\left(a-b c_{m}\right)(\Delta-r)}{K A-b R}, \\
& q_{1}^{\mathrm{MT}-\mathrm{C}}=\frac{2 I K b\left(a-b c_{m}\right)}{K A-b R} \\
& w_{2}^{\mathrm{MT}-\mathrm{C}}=\frac{4 I b c_{m}+4 I a-c_{m} \phi^{2}}{A}, \\
& p_{2}^{\mathrm{MT}-\mathrm{C}}=\frac{2 I b c_{m}+6 I a-c_{m} \phi^{2}}{A}, \\
& \theta_{2}^{\mathrm{MT}-\mathrm{C}}=\frac{\phi\left(a-b c_{m}\right)}{A}, \\
& q_{2}^{\mathrm{MT}-\mathrm{C}}=\frac{2 I b\left(a-b c_{m}\right)}{A},
\end{aligned}
$$

where $A=8 I b-\phi^{2}$ and $R=3 I b \zeta(\Delta-r)^{2}$ 
The corresponding equilibrium profits are given by

$$
\begin{aligned}
& \Pi_{C}^{\mathrm{MT}-\mathrm{C}}=\frac{I\left(a-b c_{m}\right)^{2}[K A(1+\zeta)-b \zeta R]}{A[K A-b R]}, \\
& \Pi_{R}^{\mathrm{MT}-\mathrm{C}}=\frac{4 I^{2} b\left(a-b c_{m}\right)^{2}\left[K^{2} A^{2}(1+\zeta)+b^{2} \zeta R^{2}-2 K b \zeta R A\right]}{A^{2}[K A-b R]^{2}}, \\
& \Pi_{S}^{\mathrm{MT}-\mathrm{C}}=\frac{I\left(a-b c_{m}\right)^{2}\left[K^{2} A^{2}\left(12 I b-\phi^{2}\right)(1+\zeta)+b^{2} \zeta R^{2}\left(12 I b-\phi^{2}\right)-2 K b \zeta R A\left(12 I b-\phi^{2}\right)-K b R A^{2}\right]}{A^{2}[K A-b R]^{2}} .
\end{aligned}
$$

Analogously, an interior solution can only be obtained under the premise that some conditions are satisfied. More specifically, $w_{i}^{\mathrm{MT}-\mathrm{C}}, p_{i}^{\mathrm{MT}-\mathrm{C}}, \theta_{i}^{\mathrm{MT}-\mathrm{C}}>0,0<\lambda^{\mathrm{MT}-\mathrm{C}}<1$, and $a>b p_{i}^{\mathrm{MT}-\mathrm{C}}, i=1,2$, and $A>0$ and $K A-b R>0$. Moreover, $K A>b R+I b\left(a-b c_{m}\right)(\Delta-r) \Longleftrightarrow K>\left(3 I b^{2} \zeta(\Delta-r)^{2}+I b\right.$ $\left.\left(a-b c_{m}\right)(\Delta-r)\right) /\left(8 I b-\phi^{2}\right)$; we assume these conditions to hold.

\section{Discussion}

In this section, the equilibrium strategies of different models are analyzed and compared to comprehend the effects of different cooperative structures. It is important to note that comparison of profits for the three modes pose some degree of analytical complexity, and algebraic comparison is almost impossible to complete; therefore, we resort to numerical comparison of profits in Section 6, and this kind of method is also adopted by Ghosh and Shah [36].

\subsection{Analysis of Green Manufacturing Innovation Level}

Proposition 4. The green manufacturing innovation levels satisfy the following order:

(i) $\theta_{2}^{M R-C}>\theta_{2}^{N C}=\theta_{2}^{M T-C}, \theta_{1}^{M R-C}>\theta_{1}^{M T-C}>\theta_{1}^{N C}$

(ii) $\theta_{1}^{N C}>\theta_{2}^{N C}, \theta_{1}^{M R-C}>\theta_{2}^{M R-C}, \theta_{1}^{M T-C}>\theta_{2}^{M T-C}$

Obviously, whether in the first period or the second period, the green manufacturing innovation level of MR-C mode is always the highest. The manufacturer is the leader of green manufacturing innovation and is familiar with its products, and the retailer grasps the consumers' demand for products with green features accurately; these are the primary reasons of this result.

Through a longitudinal comparison of the three modes, we can find that the green manufacturing innovation levels in period 1 are higher than in period 2; it is mainly because of the absence of collection activity in period 1; hence, the manufacturer can invest more resources to improve the green manufacturing levels. Overall, the cooperation of the manufacturer and retailer can achieve better green manufacturing efficiency.

\section{Corollary 1}

(i) $\left(\partial \theta_{i}^{N C} / \partial a\right)>0,\left(\partial \theta_{i}^{N C} / \partial c_{m}\right)<0,\left(\partial \theta_{i}^{N C} / \partial I\right)<0$, $\left(\partial \theta_{i}^{N C} / \partial \phi\right)>0$

(ii) $\left(\partial \theta_{i}^{M R-C} / \partial a\right)>0,\left(\partial \theta_{i}^{M R-C} / \partial c_{m}\right)<0$, $\left(\partial \theta_{i}^{M R-C} / \partial I\right)<0,\left(\partial \theta_{i}^{M R-C} / \partial \phi\right)>0$

(iii) $\left(\partial \theta_{i}^{M T-C} / \partial a\right)>0,\left(\partial \theta_{i}^{M T-C} / \partial c_{m}\right)<0$, $\left(\partial \theta_{i}^{M T-C} / \partial I\right)<0,\left(\partial \theta_{i}^{M T-C} / \partial \phi\right)>0$

In the three modes, the green manufacturing innovation levels are monotonic increasing functions of the market potential $a$ and consumer's sensitivity to green products $\phi$. Conversely, they are monotonic decreasing functions of unit cost of production $c_{m}$ and investment parameter of green manufacturing innovation $I$.

Corollary 1 implies that the increase in potential market and consumer's green sensitivity will enhance manufacturer's confidence in green manufacturing; hence, the level of green manufacturing innovation will increase. However, the increase of the manufacturing cost and investment parameter of green manufacturing is a kind of economic pressure for the manufacture, which has a decreasing impact on the green manufacturing innovation level.

\subsection{Analysis of Price}

Proposition 5. The relations of the wholesale prices and retail prices are given by

(i) $w_{2}^{N C}=w_{2}^{M T-C}, w_{1}^{N C}>w_{1}^{M T-C}$

(ii) $w_{2}^{N C}>w_{1}^{N C}, w_{2}^{M T-C}>w_{1}^{M T-C}$

(iii) $p_{2}^{N C}=p_{2}^{M T-C}>p_{2}^{M R-C}, p_{1}^{N C}>p_{1}^{M T-C}>p_{1}^{M R-C}$

(iv) $p_{2}^{N C}>p_{1}^{N C}, p_{2}^{M R-C}>p_{1}^{M R-C}, p_{2}^{M T-C}>p_{1}^{M T-C}$

Proposition 5 suggests that the wholesale price is lower in MT-C mode than that in NC mode. The partnership between the manufacturer and the third-service provider reduces the wholesale price; therefore, collaboration is more beneficial from the recycler's perspective. On the contrary, the retail price in MR-C mode is always the lowest; the main reason for this 
result is the disappearance of wholesale process in the cooperative organization, which reduces the costs of the retailer. Therefore, from the standpoint of consumers, the MR-C mode is optimal because of its lowest price.

The longitudinal comparisons of the wholesale price and retail price show that these two prices are higher in period 1 invariably. However, according to common sense, the technology will be more mature and the market will be more stable in period 2, so the price should be lower. In this paper, due to the consideration of the used-product collection activity in period 2, the manufacturer will invest more to implement CLSC management, which increases the price.

\section{Corollary 2}

(i) $\left(\partial w_{i}^{N C} / \partial a\right)>0,\left(\partial w_{i}^{N C} / \partial c_{m}\right)>0,\left(\partial w_{i}^{N C} / \partial I\right)<0$, $\left(\partial w_{i}^{N C} / \partial \phi\right)>0$

(ii) $\left(\partial w_{i}^{M T-C} / \partial a\right)>0,\left(\partial w_{i}^{M T-C} / \partial c_{m}\right)>0$, $\left(\partial w_{i}^{M T-C} / \partial I\right)<0,\left(\partial w_{i}^{M T-C} / \partial \phi\right)>0$

(iii) $\left(\partial P_{i}^{N C} / \partial a\right)>0,\left(\partial P_{i}^{N C} / \partial c_{m}\right)>0$, $\left(\partial P_{i}^{N C} / \partial I\right)<0,\left(\partial P_{i}^{N C} / \partial \phi\right)>0$

(iv) $\left(\partial p_{i}^{M R-C} / \partial a\right)>0,\left(\partial p_{i}^{M R-C} / \partial c_{m}\right)>0$, $\left(\partial p_{i}^{M R-C} / \partial I\right)<0,\left(\partial p_{i}^{M R-C} / \partial \phi\right)>0$

(v) $\left(\partial p_{i}^{M T-C} / \partial a\right)>0,\left(\partial p_{i}^{M T-C} / \partial c_{m}\right)>0$, $\left(\partial p_{i}^{M T-C} / \partial I\right)<0,\left(\partial p_{i}^{M T-C} / \partial \phi\right)>0$

Some inspirations can be obtained from Corollary 2. For instance, if $a$ and $c_{m}$ increase, the manufacturer will sell its products to the retailer at a higher wholesale price to get higher profits; thus, the retailer reasonably sells products to the consumers at a higher retail price. Because of the positive impact of $\phi$ on demand, therefore, the increase of $\phi$ will lead to an increase in demand, and then the demand exceeds supply causing the rise of retail price. However, the increase of I will lower the price. As mentioned in the previous propositions, I represents the difficulty of innovating, and the increase of I will reduce the collection rate and green manufacturing innovation level at the same time, in which case the manufacturer will invest less in green manufacturing innovation and recycling; the total cost is reduced, thus reducing the wholesale price and retail price.

\subsection{Analysis of Demand}

Proposition 6. The demands satisfy the following order:

(i) $q_{2}^{M R-C}>q_{2}^{N C}=q_{2}^{M T-C}, q_{1}^{M R-C}>q_{1}^{M T-C}>q_{1}^{N C}$

(ii) $q_{1}^{N C}>q_{2}^{N C}, q_{1}^{M T-C}>q_{2}^{M T-C}, q_{1}^{M R-C}>q_{2}^{M R-C}$

Obviously, the CLSC system enjoys the highest sales volume in both periods if the manufacture cooperates with the retailer. By combining the conclusions mentioned in Propositions 4 and 5, the aforesaid result can be intuitively drawn on account of the lowest price and the highest green manufacturing innovation level of $M R-C$ mode. This explanation also applies to the longitudinal comparisons of the demand. In general, all the CLSC members can benefit from the cooperation of the manufacturer and retailer (MR-C mode).

\section{Corollary 3}

(i) $\left(\partial q_{i}^{N C} / \partial a\right)>0,\left(\partial q_{i}^{N C} / \partial c_{m}\right)<0,\left(\partial q_{i}^{N C} / \partial I\right)<0$, $\left(\partial q_{i}^{N C} / \partial \phi\right)>0$

(ii) $\left(\partial q_{i}^{M R-C} / \partial a\right)>0,\left(\partial q_{i}^{M R-C} / \partial c_{m}\right)<0$, $\left(\partial q_{i}^{M R-C} / \partial I\right)<0,\left(\partial q_{i}^{M R-C} / \partial \phi\right)>0$

(iii) $\left(\partial q_{i}^{M T-C} / \partial a\right)>0,\left(\partial q_{i}^{M T-C} / \partial c_{m}\right)<0$, $\left(\partial q_{i}^{M T-C} / \partial I\right)<0,\left(\partial q_{i}^{M T-C} / \partial \phi\right)>0$

It is observed that the demand increases as a and $\phi$ increase, but decreases as $c_{m}$ and I increase. According to the demand function assumed in this paper, $a$ and $\phi$ have a positive impact on the demand clearly. However, the rising cost of manufacturing can lead to a higher retail price, and then a reduction in demand appears. As mentioned in Proposition 4, there is a negative correlation between I and $\theta$; the increase of I implies that $\theta$ will decrease, eventually causing a reduction in demand.

\subsection{Analysis of Collection Rate}

Proposition 7. The collection rates satisfy the following order:

$$
\lambda^{\mathrm{MT}-\mathrm{C}}>\lambda^{\mathrm{MR}-\mathrm{C}}>\lambda^{\mathrm{NC}}
$$

From Proposition 6, we see that the demands satisfy $q_{2}^{M R-C}>q_{2}^{N C}=q_{2}^{M T-C}$ and $q_{1}^{M R-C}>q_{1}^{M T-C}>q_{1}^{N C}$; thus, the collection rate should be naturally the highest in MR-C mode. However, it is unexpected to notice that the collection rate in $M R-C$ mode is relatively low; this can be attributed to the cooperation of the manufacturer and third-service provider. First of all, the manufacturer is familiar with its products and possesses the ability to accurately determine the parts of used products that can be recycled efficiently; hence, the manufacturer will share product information with the third-service provider after establishing partnership so as to make the process of recycling more precise and purposeful. Secondly, the thirdservice provider is able to communicate with the manufacturer about the collection activity whenever necessary. Furthermore, it is observed that the collection rate is always the lowest in NC mode; this illustrates that collaboration is conducive to resources recovery and circular economy.

\section{Corollary 4}

(i) $\left(\partial \lambda^{N C} / \partial a\right)>0,\left(\partial \lambda^{N C} / \partial c_{m}\right)<0$, $\left(\partial \lambda^{N C} / \partial I\right)<0,\left(\partial \lambda^{N C} / \partial \phi\right)>0$

(ii) $\left(\partial \lambda^{M R-C} / \partial a\right)>0,\left(\partial \lambda^{M R-C} / \partial c_{m}\right)<0$, $\left(\partial \lambda^{M R-C} / \partial I\right)<0,\left(\partial \lambda^{M R-C} / \partial \phi\right)>0$

(iii) $\left(\partial \lambda^{M T-C} / \partial a\right)>0,\left(\partial \lambda^{M T-C} / \partial c_{m}\right)<0$, $\left(\partial \lambda^{M T-C} / \partial I\right)<0,\left(\partial \lambda^{M T-C} / \partial \phi\right)>0$

Corollary 4 reveals that, with the increasing of a and $\phi$, the third-service provider will correspondingly improve its 
efficiency of used-products collection. This can be put down to the positive role of these two parameters in boosting demand, which directly affects the number of products that can be recycled as well as the collection rate. However, the collection efficiency will decrease with the increasing $c_{m}$ and I, which can be attributed to their negative impact on demand. Therefore, the reduced demand leads to a decrease in the amount of recyclable used products and reduces the recovery efficiency ultimately.

5.5. Coordination Mechanism. According to the previous analysis, we can observe that the cooperation of the manufacturer and retailer (MR-C mode) is optimal. Therefore, a coordination mechanism of this mode is designed to maximize the operational efficiency of CLSC. Given that the assumptions and symbol definitions in Section 3 are satisfied, the objective function of CLSC under centralized decision-making is as follows:

$$
\begin{aligned}
\operatorname{MAX} \Pi^{\mathrm{CC}}= & \left(p_{1}^{\mathrm{CC}}-c_{m}\right)\left(a-b p_{1}^{\mathrm{CC}}+\phi \theta_{1}^{\mathrm{CC}}\right)-I\left(\theta_{1}^{\mathrm{CC}}\right)^{2} \\
& +\zeta\left[\left(p_{2}^{\mathrm{CC}}-c_{m}\right)\left(a-b p_{2}^{\mathrm{CC}}+\phi \theta_{2}^{\mathrm{CC}}\right)\right. \\
& +\lambda^{\mathrm{CC}}(\Delta-r)\left(a-b p_{1}^{\mathrm{CC}}+\phi \theta_{1}^{\mathrm{CC}}\right) \\
& \left.-I\left(\theta_{2}^{\mathrm{CC}}\right)^{2}-K\left(\lambda^{\mathrm{CC}}\right)^{2}\right] .
\end{aligned}
$$

Subject to $p_{i}^{\mathrm{CC}}, \theta_{i}^{\mathrm{CC}}>0,0<\lambda^{\mathrm{CC}}<1$, and $a>b p_{-} i^{\mathrm{CC}}=1,2$

The same method is adopted for calculation; the optimal decisions and profit of centralized CLSC can be obtained as follows:

$$
\begin{aligned}
& p_{2}^{\mathrm{CC}}=\frac{2 I\left(a+b c_{m}\right)-c_{m} \phi^{2}}{Q}, \\
& \theta_{2}^{\mathrm{CC}}=\frac{\phi\left(a-b c_{m}\right)}{Q}, \\
& p_{1}^{\mathrm{CC}}=\frac{2 I K\left(a+b c_{m}\right)-K c_{m} \phi^{2}-a Y}{K Q-b Y}, \\
& \theta_{1}^{\mathrm{CC}}=\frac{K \phi\left(a-b c_{m}\right)}{K Q-b Y}, \\
& \lambda^{\mathrm{CC}}=\frac{I b(\Delta-r)\left(a-b c_{m}\right)}{K Q-b Y}, \\
& \Pi^{\mathrm{CC}}=\frac{I\left(a-b c_{m}\right)^{2}[K Q(1+\zeta)-b \zeta Y]}{Q[K Q-b Y]},
\end{aligned}
$$

$$
\text { where } Q=4 I b-\phi^{2}, \quad Y=I b \zeta(\Delta-r)^{2} \text {, }
$$$$
\text { and }
$$
$B=2 \operatorname{Ib} \zeta\left(\Delta-c_{f}\right)\left(c_{f}-r\right)$.

It is apparent that the following conclusions hold, i.e., $p_{2}^{\mathrm{CC}}=p_{2}^{\mathrm{MR}-\mathrm{C}}, \theta_{2}^{\mathrm{CC}}=\theta_{2}^{\mathrm{MR}-\mathrm{C}}, p_{1}^{\mathrm{CC}}<p_{1}^{\mathrm{MR}-\mathrm{C}}, \theta_{1}^{\mathrm{CC}}>\theta_{1}^{\mathrm{MR}-\mathrm{C}}, \lambda^{\mathrm{CC}}$ $>\lambda^{\mathrm{MR}-\mathrm{C}}, \Pi^{\mathrm{CC}}>\Pi_{\mathrm{S}}^{\mathrm{MR}-\mathrm{C}}, q_{1}^{\mathrm{CC}}>q_{1}^{\mathrm{MR}-\mathrm{C}}$, and $q_{2}^{\mathrm{CC}}=q_{2}^{\mathrm{MR}-\mathrm{C}}$ can be obtained via comparison of price. Therefore, compared with the centralized CLSC, the green manufacturing innovation level, collection rate, and total profit are lower in decentralized CLSC while the price is higher; thus, the operational efficiency of CLSC is not optimal. Although centralized decision-making can maximize the performance of the system, it is difficult to achieve in practice. Therefore, a coordination mechanism should be proposed by the cooperative organization composed of the manufacturer and retailer to maximize the efficiency of CLSC while ensuring that the interests of members will not be affected. Based on the existing research, we design a mechanism $\left\{\lambda^{\mathrm{MR}-\mathrm{CC}}, F^{\mathrm{MR}-\mathrm{CC}}\right\}$ to coordinate CLSC. More specifically, the third-service provider pays a fixed agency fee $F^{\mathrm{MR}-\mathrm{CC}}$ to the cooperative organization for the qualification to conduct used-product collection and completes the target collection rate $\lambda^{M R-C C}$. Then, the cooperative organization determines the retail price and green manufacturing innovation level. The objective function under coordination mechanism can be formulated as follows:

$$
\begin{aligned}
& (\mathrm{CC}) \mathrm{MAX} \Pi_{\mathrm{CC}}^{\mathrm{MR}-\mathrm{CC}}=\left(p_{1}^{\mathrm{MR}-\mathrm{CC}}-c_{m}\right)\left(a-b p_{1}^{\mathrm{MR}-\mathrm{CC}}+\phi \theta_{1}^{\mathrm{MR}-\mathrm{CC}}\right) \\
& -I\left(\theta_{1}^{\mathrm{MR}-\mathrm{CC}}\right)^{2}+\xi\left[\left(p_{2}^{\mathrm{MR}-\mathrm{CC}}-c_{m}\right)\right. \\
& \cdot\left(a-b p_{2}^{\mathrm{MR}-\mathrm{CC}}+\phi \theta_{2}^{\mathrm{MR}-\mathrm{CC}}\right)+\lambda^{\mathrm{MR}-\mathrm{CC}} \\
& \cdot\left(\Delta-c_{f}\right)\left(a-b p_{1}^{\mathrm{MR}-\mathrm{CC}}+\phi \theta_{1}^{\mathrm{MR}-\mathrm{CC}}\right) \\
& \left.-I\left(\theta_{2}^{\mathrm{MR}-\mathrm{CC}}\right)^{2}\right]+F^{\mathrm{MR}-\mathrm{CC}} \\
& \mathrm{S} . \mathrm{T}\left\{\begin{array}{l}
\lambda^{\mathrm{MR}-\mathrm{CC}}=\frac{I b(\Delta-r)\left(a-b c_{m}\right)}{K Q-b Y} \\
\Pi_{\mathrm{TC}}^{\mathrm{MR}-\mathrm{CC}}=\zeta\left[\lambda^{\mathrm{MR}-\mathrm{CC}}\left(c_{f}-r\right)\right. \\
\left(a-b p_{1}^{\mathrm{MR}-\mathrm{CC}}+\phi \theta_{1}^{\mathrm{MR}-\mathrm{CC}}\right) \\
\left.-K\left(\lambda^{\mathrm{MR}-\mathrm{CC}}\right)^{2}\right]-F^{\mathrm{MR}-\mathrm{CC}} \geq \Pi_{\mathrm{T}}^{\mathrm{MR}-\mathrm{C}} .
\end{array}\right.
\end{aligned}
$$

Subject to $p_{i}^{\mathrm{MR}-\mathrm{CC}}, \theta_{i}^{\mathrm{MR}-\mathrm{CC}}>0,0<\lambda^{\mathrm{MR}-\mathrm{CC}}<1$, and $a>b$ $p_{i}^{\mathrm{MR}-\mathrm{CC}}, i=1,2$

In the above two constraints, the first one is similar to the incentive compatibility constraint while the second one is an individual rationality constraint, i.e., the third-service provider will accept the coordination mechanism only when his profit is not less than that in the decentralized CLSC. Again, we can get the following optimal decisions and maximum profits under the coordination mechanism: 


$$
\begin{aligned}
p_{2}^{\mathrm{MR}-\mathrm{CC}} & =\frac{2 I\left(a+b c_{m}\right)-c_{m} \phi^{2}}{Q}, \\
\theta_{2}^{\mathrm{MR}-\mathrm{CC}} & =\frac{\phi\left(a-b c_{m}\right)}{Q}, \\
p_{1}^{\mathrm{MR}-\mathrm{CC}} & =\frac{2 I K\left(a+b c_{m}\right)-K c_{m} \phi^{2}-a Y}{K Q-b Y}, \\
\theta_{1}^{\mathrm{MR}-\mathrm{CC}} & =\frac{K \phi\left(a-b c_{m}\right)}{K Q-b Y}, \\
\lambda^{\mathrm{MR}-\mathrm{CC}} & =\frac{I b(\Delta-r)\left(a-b c_{m}\right)}{K Q-b Y}, \\
F^{\mathrm{MR}-\mathrm{CC}} & =\frac{-I^{2} K b^{2} \zeta\left(a-b c_{m}\right)^{2}(\Delta-r)\left(\Delta-2 c_{f}+r\right)}{[K Q-b Y]^{2}}-\frac{I^{2} K b^{2} \zeta\left(a-b c_{m}\right)^{2}\left(c_{f}-r\right)^{2}}{[K Q-b B]^{2}} \\
\Pi_{\mathrm{SCC}}^{\mathrm{MR}-\mathrm{CC}} & =\frac{I\left(a-b c_{m}\right)^{2}[K Q(1+\zeta)-b \zeta Y]}{\mathrm{MR}-\mathrm{CC}}=\frac{I(K Q-b Y]}{\left[K Q-b c_{m}\right)^{2}[K Q(1+\zeta)-b \zeta Y]}, \frac{I^{2} K b^{2} \zeta\left(a-b c_{m}\right)^{2}\left(c_{f}-r\right)^{2}}{[K Q-b B]^{2}}, \\
\Pi_{\mathrm{TC}}^{\mathrm{MR}-\mathrm{CC}} & =\frac{I^{2} K b^{2} \zeta\left(a-b c_{m}\right)^{2}\left(c_{f}-r\right)^{2}}{[K Q-b B]^{2}},
\end{aligned}
$$

Compared with the results of centralized CLSC and decentralized CLSC without coordination mechanism, the following conclusions can be obtained $\theta_{2}^{\mathrm{MR}-\mathrm{CC}}=\theta_{2}^{\mathrm{CC}}=$ $\theta_{2}^{\mathrm{MR}-\mathrm{C}}, p_{1}^{\mathrm{MR}-\mathrm{CC}}=p_{1}^{\mathrm{CC}}<p_{1}^{\mathrm{MR}-\mathrm{C}}, \quad \theta_{1}^{\mathrm{MR}-\mathrm{CC}}=\theta_{1}^{\mathrm{CC}}>\theta_{1}^{\mathrm{MR}-\mathrm{C}}$, $\lambda^{\mathrm{MR}-\mathrm{CC}}=\lambda^{\mathrm{CC}}>\lambda^{\mathrm{MR}-\mathrm{C}}, \Pi_{\mathrm{CC}}^{\mathrm{MR}-\mathrm{CC}}>\Pi_{\mathrm{C}}^{\mathrm{MR}-\mathrm{C}}, \Pi_{\mathrm{TC}}^{\mathrm{MR}-\mathrm{CC}}=\Pi_{\mathrm{T}}^{\mathrm{MR}-\mathrm{C}}$, and $\Pi_{\mathrm{SCC}}^{\mathrm{MR}-\mathrm{CC}}=\Pi^{\mathrm{CC}}>\Pi_{\mathrm{S}}^{\mathrm{MR}-\mathrm{C}}$. It is intuitive to note that the operational efficiency is improved obviously due to the coordination mechanism, and the profit of the third-service provider has not been affected. In addition, the increase in profit of cooperative organization is determined by its market dominance, which is also its motivation to actively coordinate the supply chain.

\section{Numerical Analysis}

In this section, numerical examples are presented to intuitively analyze the coordination mechanism; the impact of $a$, $\phi, c_{m}$, and $I$ on equilibrium strategies are visualized through images. Then, the impact of $\zeta$ on profits is shown graphically to draw some conclusions and propose more management inspirations. In order to comply with particular conditions and the assumptions of this paper, specific values will be assigned to parameters.

The numerical results of coordination mechanism: $a=600, K=5000, b=10, c_{m}=50, \Delta=35, c_{f}=20, r=6$, $\zeta=0.8, I=100$, and $\phi=5$ (refer Table 1$)$.

The impact of $a, \phi, c_{m}$, and I: the values of common parameters are as follows: $K=5000, b=10, \Delta=35, c_{f}=20$, and $r=6, \zeta=0.8$. With the values of $a, \phi, c_{m}$, and I varying in the range of 600 to 700,5 to 30,50 to 60 , and 100 to 500 , respectively (refer Figures 2-6).

6.1. Analysis of Coordination Mechanism and Equilibrium Strategies. The corresponding numerical results are summarized in Table 1.

Results in Table 1 prove the effectiveness of coordination mechanism proposed in Section 5.5, and the efficiency of the closed-loop supply chain system is improved.

As shown in Figures 2-6, the relationships between equilibrium strategies in different modes are presented intuitively and consistent with Proposition 4-7. Moreover, it is obvious to observe that the impact of $a, \phi, c_{m}$, and $I$ on equilibrium strategies is depicted clearly in Figures 2-6, which confirms the rationality of Corollary 1-4 as well. The numerical examples of decision variables are also in line with actual conditions. Taking the automotive industry as an example, the wholesale price of a car is mainly affected by its manufacturing expense, and the wholesale price directly affects the retail price, so the effect of cost on the retail price is also obvious. The price increases with the cost, while the demand will decrease due to the higher price. Furthermore, the impacts of consumers, preference for green manufacturing products and potential market demand on retail price are significant as well. For instance, if the automobile manufacturer observes that the potential market for new energy vehicles is large and consumers are willing to buy them, the price of new energy vehicles will increase without government subsidies. Simultaneously, the automaker will 
TABLE 1: The effect of the coordination mechanism.

\begin{tabular}{|c|c|c|c|c|c|c|c|c|c|c|c|c|}
\hline Mode & $w_{1}$ & $w_{2}$ & $p_{1}$ & $p_{2}$ & $q_{1}$ & $q_{2}$ & $\theta_{1}$ & $\theta_{2}$ & $\lambda$ & $\Pi_{\mathrm{MR}}$ & $\Pi_{\mathrm{T}}$ & $\Pi_{\mathrm{S}}$ \\
\hline $\mathrm{MR}$ & N/A & N/A & 54.02 & 55.03 & 60.55 & 50.31 & 0.15 & 0.13 & 0.08 & 504.01 & 28.74 & 532.76 \\
\hline MR-CC & $\mathrm{N} / \mathrm{A}$ & N/A & 52.49 & 55.03 & 76.05 & 50.31 & 0.19 & 0.13 & 0.22 & 552.83 & 28.74 & 581.57 \\
\hline
\end{tabular}
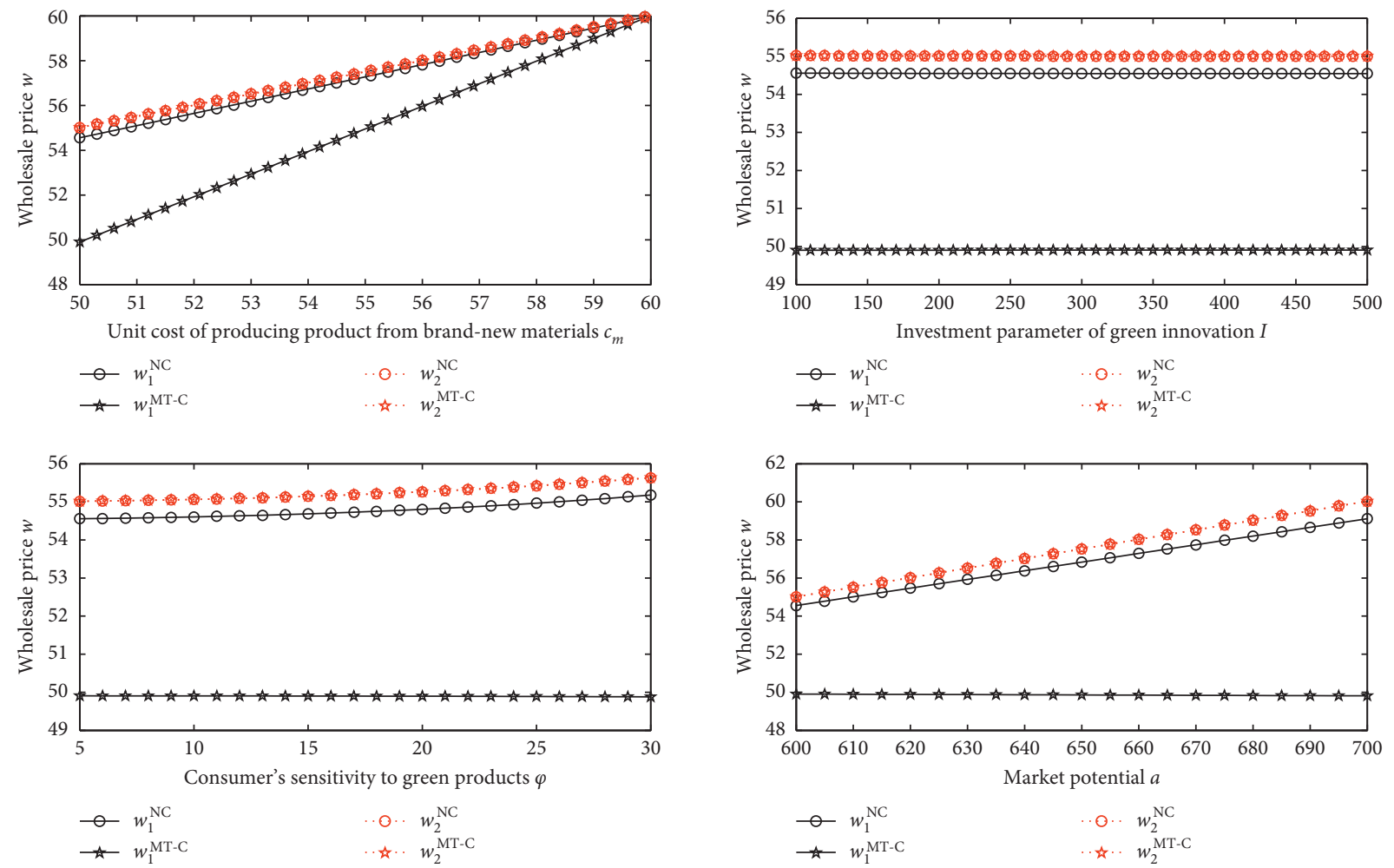

Figure 2: Analysis of the wholesale price.

invest more in new energy vehicles which will lead to a corresponding increase in the green manufacturing innovation level. However, if the manufacturing expense is relatively high, it will aggravate the cost burden of the enterprise and reduce the green manufacturing innovation level.

6.2. Analysis of Profits. In this part, profits in different modes and the impact of $\zeta$ are analyzed. The values of parameters are as follows: $a=600, K=5000, b=10, c_{m}=50, \Delta=35$, $c_{f}=20, r=6, \zeta=0.8, I=100$, and $\phi=5$, and $\zeta$ is varied from 0 to 1 . In order to confirm whether cooperation has a positive impact on profits, the sum of manufacturer's and retailer's profits in the $\mathrm{NC}$ mode is regarded as the benchmark of the MR-C mode, similarly, and the aggregated profit of the manufacturer and third-service provider is the benchmark of the MT-C mode. The explanation mentioned above is important for profit comparing and analyzing. The numerical examples are depicted in Figures 7-9.

(i) The relationships of profits among cooperation and noncooperation scenarios are as follows (refer Figure 7):

$$
\begin{aligned}
& \Pi_{\mathrm{C}}^{\mathrm{MR}-\mathrm{C}}>\Pi_{\mathrm{M}+\mathrm{R}}^{\mathrm{NC}}, \\
& \Pi_{\mathrm{C}}^{\mathrm{MT}-\mathrm{C}}>\Pi_{\mathrm{M}+\mathrm{T}}^{\mathrm{NC}}, \\
& \Pi_{\mathrm{C}}^{\mathrm{MR}-\mathrm{C}}>\Pi_{\mathrm{C}}^{\mathrm{MT}-\mathrm{C}} .
\end{aligned}
$$

Obviously, Figure 7 indicates that the cooperative organization can obtain a higher profit invariably. Furthermore, the profit of cooperation organization in the MR-C mode exceeds the MT-C scenario, from the propositions mentioned previously; it is not difficult to observe that the MR-C mode enjoys the highest green manufacturing innovation level and market demand, as well as the lowest price; these factors are important in improving profit. Therefore, the manufacturer should actively establish partnership with supply chain members, and the retailer is the most outstanding partner.

(ii) The profits of the retailer and third-service provider satisfy the following order (refer Figure 8):

$$
\begin{gathered}
\Pi_{\mathrm{R}}^{\mathrm{MT}-\mathrm{C}}>\Pi_{\mathrm{R}}^{\mathrm{NC}}, \\
\Pi_{\mathrm{T}}^{\mathrm{MR}-\mathrm{C}}>\Pi_{\mathrm{T}}^{\mathrm{NC}} .
\end{gathered}
$$



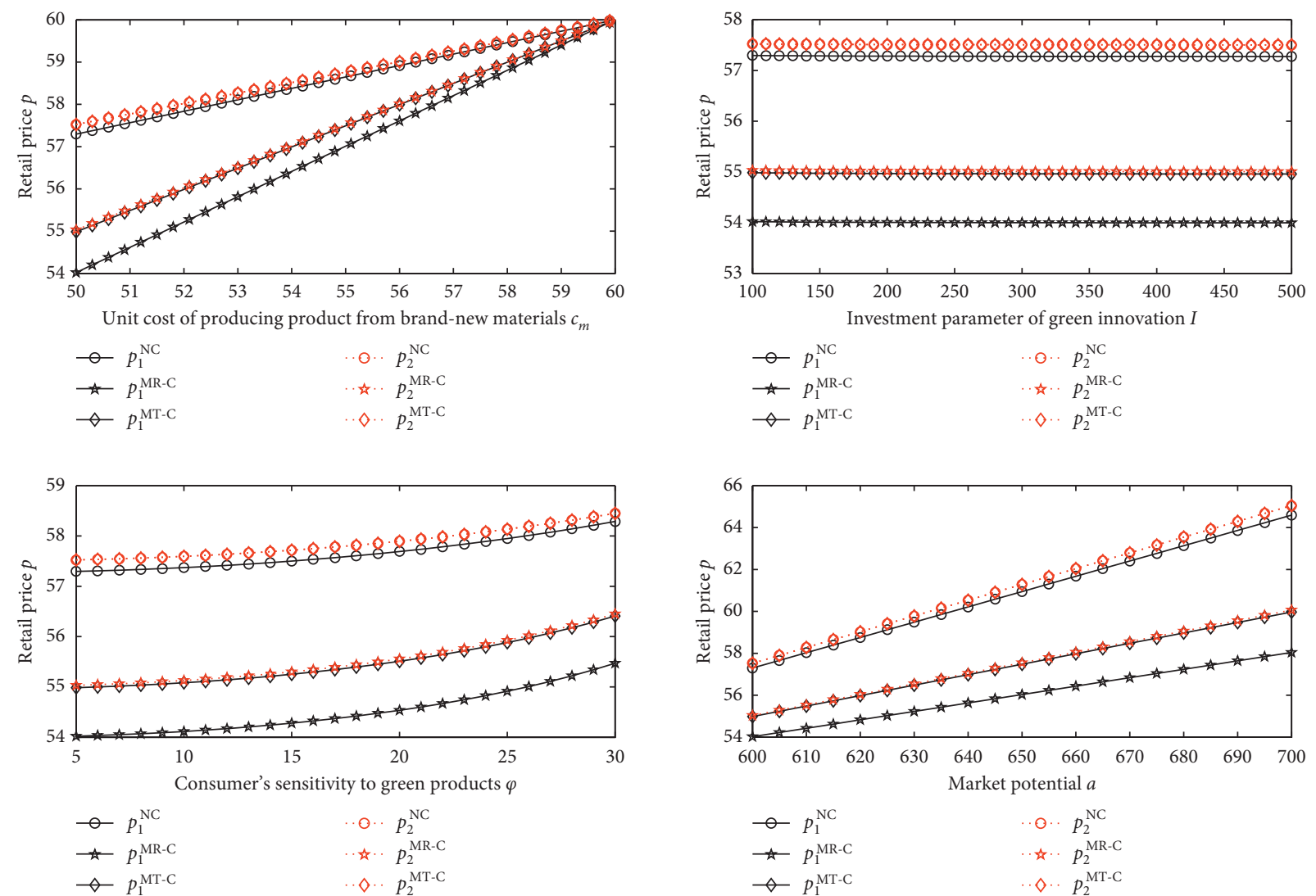

Figure 3: Analysis of the retail price.
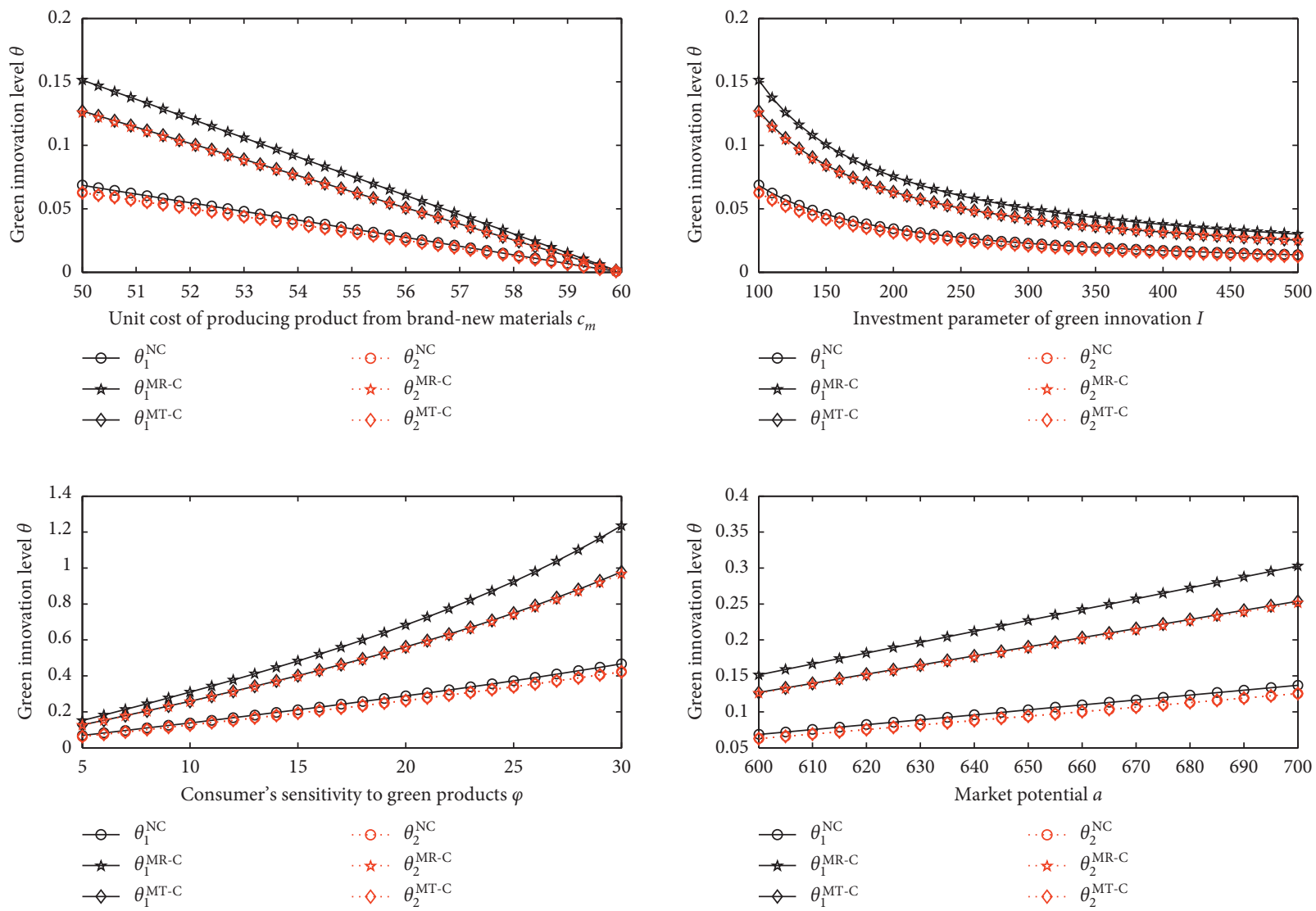

Figure 4: Analysis of the green manufacturing innovation level. 

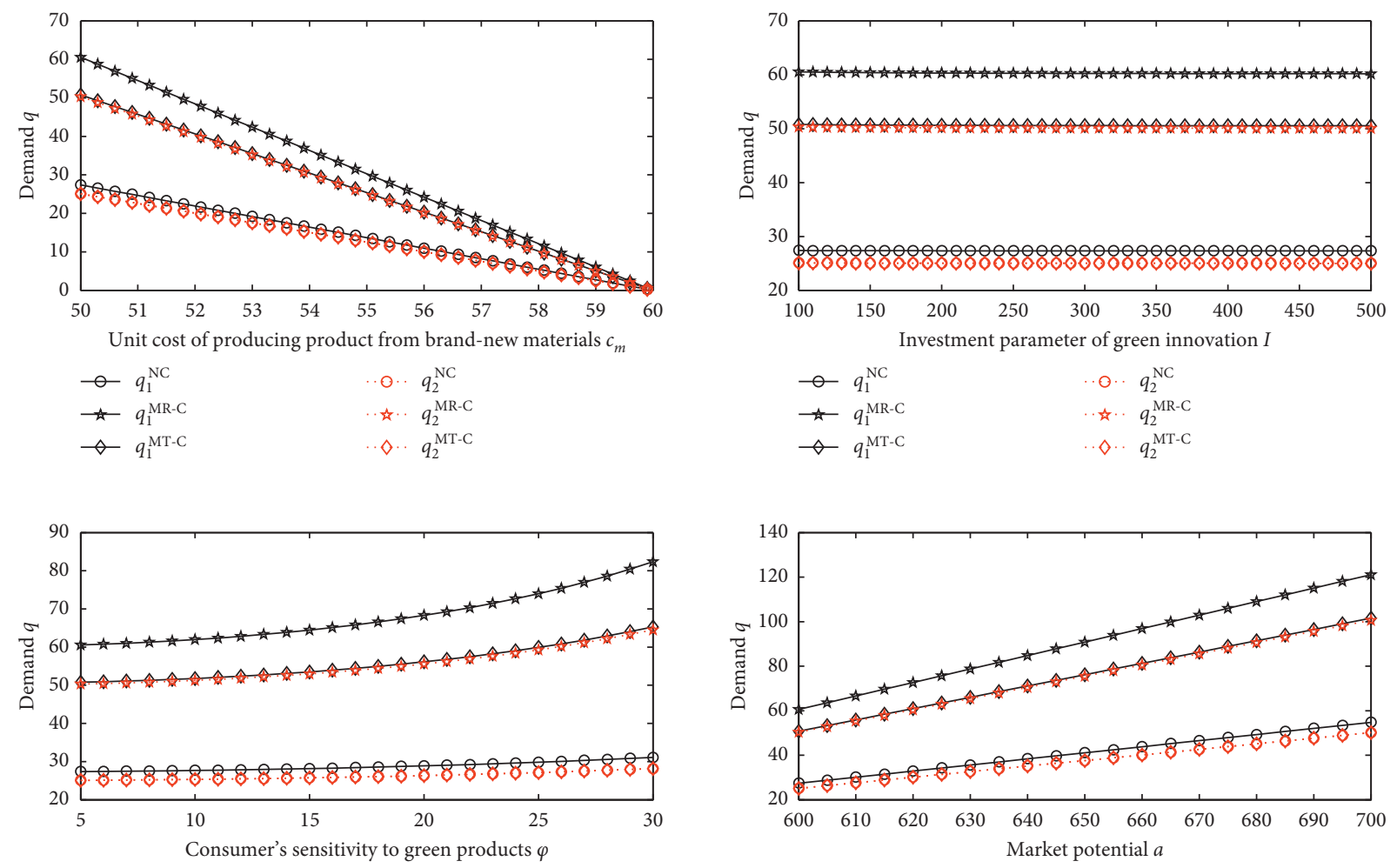
$\multimap q_{1}^{\mathrm{NC}}$
$\approx q_{1}^{\mathrm{MR}-\mathrm{C}}$
O.. $q_{2}^{\mathrm{NC}}$
$\neg q_{1}^{\mathrm{MT}-\mathrm{C}}$
- . . . $q_{2}^{\mathrm{MR}-\mathrm{C}}$
$\diamond \cdots q_{2}^{\mathrm{MT}-\mathrm{C}}$

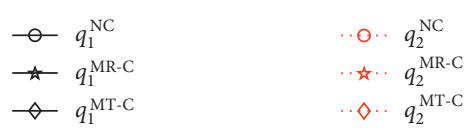

Figure 5: Analysis of demand.
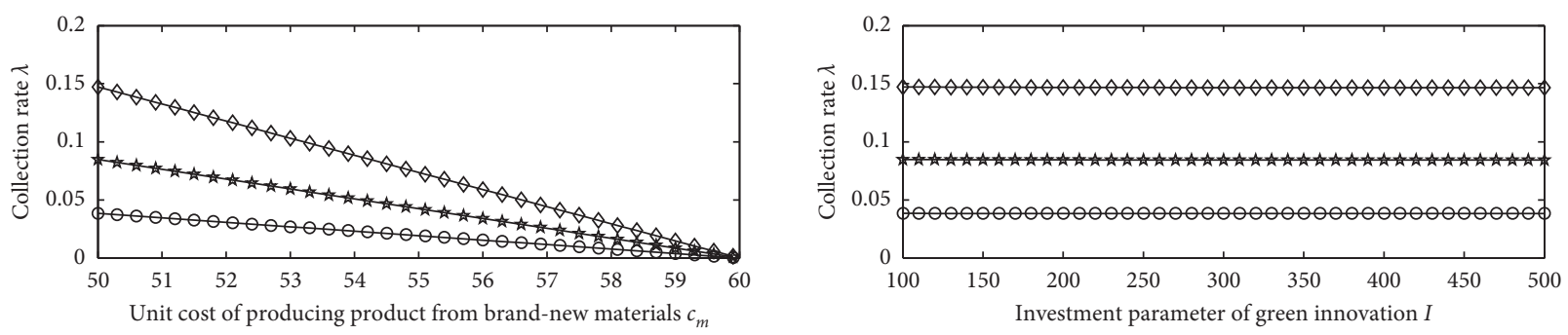

$-\lambda^{\mathrm{NC}}$

$\star \lambda^{\mathrm{MR}-\mathrm{C}}$

$\neg \lambda^{\mathrm{MT}-\mathrm{C}}$

$-\lambda^{\mathrm{NC}}$

\# $\lambda^{\mathrm{MR}-\mathrm{C}}$

$\neg \lambda^{\mathrm{MT}-\mathrm{C}}$
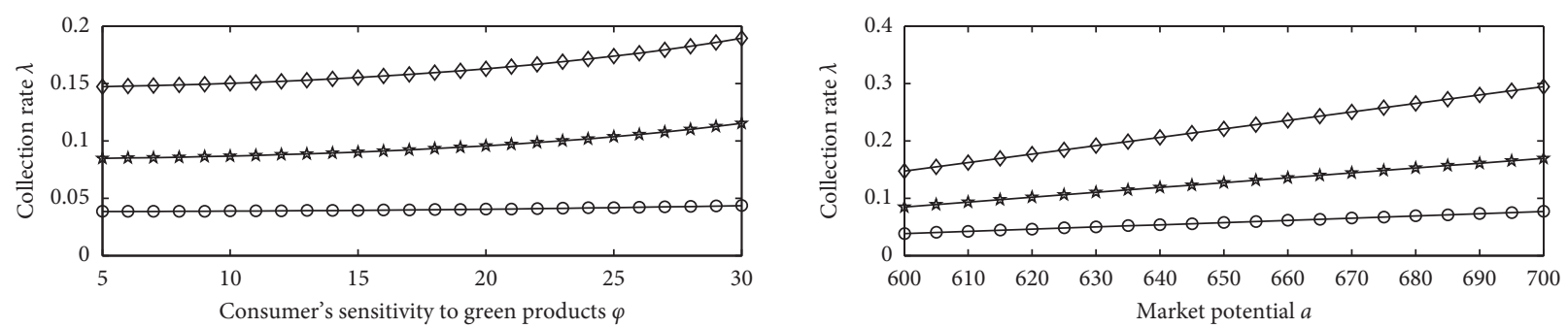

$-\lambda^{\mathrm{NC}}$

$\star \lambda^{\mathrm{MR}-\mathrm{C}}$

$\neg \lambda^{\mathrm{MT}-\mathrm{C}}$

$$
\begin{aligned}
& -\lambda^{\mathrm{NC}} \\
& \approx \lambda^{\mathrm{MR}-\mathrm{C}} \\
& \diamond \lambda^{\mathrm{MT}-\mathrm{C}}
\end{aligned}
$$

Figure 6: Analysis of the collection rate. 


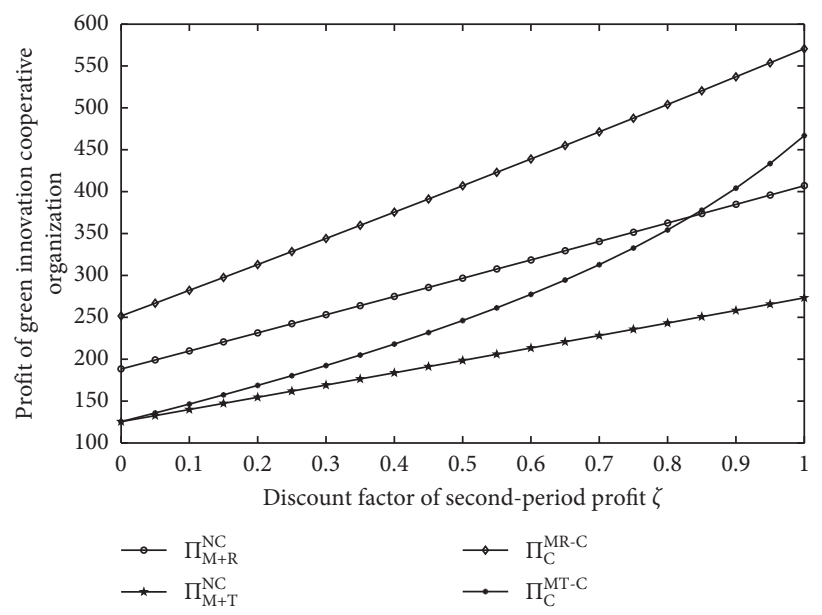

Figure 7: Analysis of cooperative organization's profit.

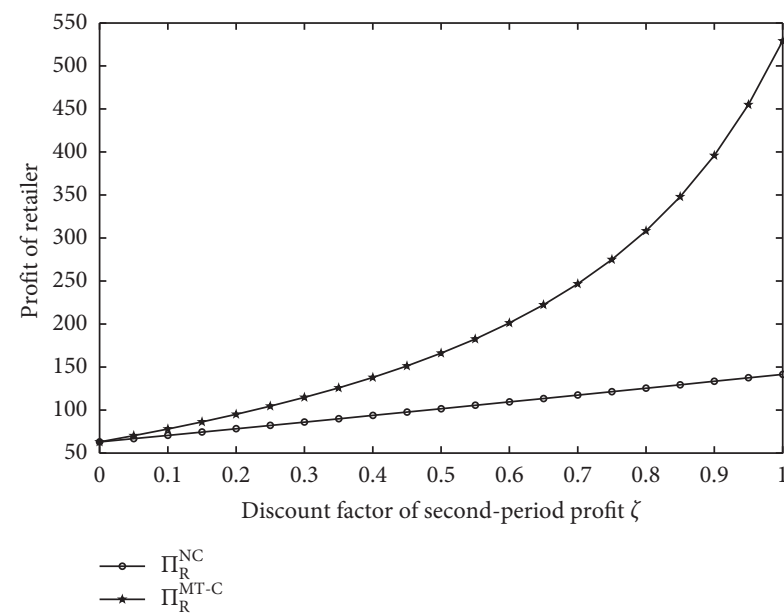

(a)

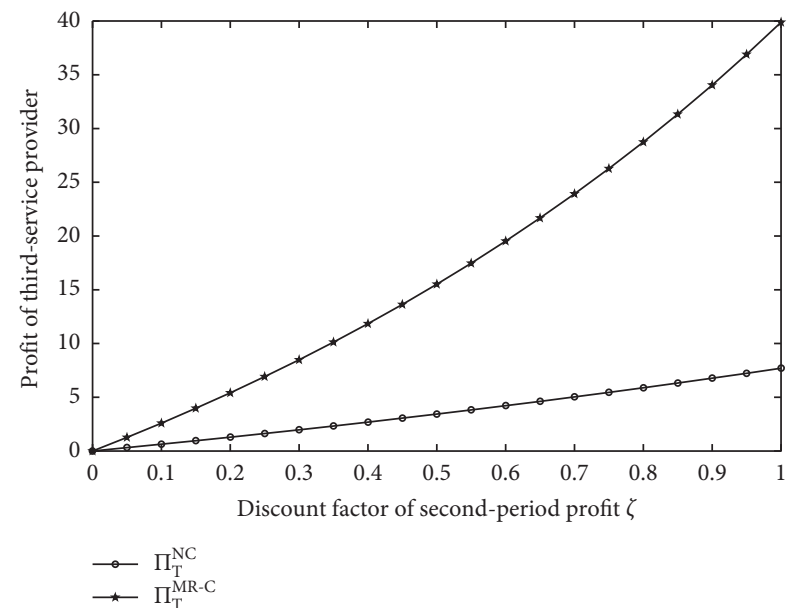

(b)

FIgURE 8: Analysis of nonparticipating partners' profit.

It is natural to find that the profits of the retailer and third-service provider under cooperation scenarios are higher. Again, Figure 8 proves the advantages of cooperation, which is not only conducive to both parties in the partnership but also beneficial to the rest of the CLSC members.

(iii) The total profits of the CLSC system satisfy the following order (refer Figure 9):

$$
\begin{array}{ll}
\Pi_{\mathrm{S}}^{\mathrm{MT}-\mathrm{C}}>\Pi_{\mathrm{S}}^{\mathrm{MR}-\mathrm{C}}>\Pi_{\mathrm{S}}^{\mathrm{NC}}, & \text { if } \varsigma \text { is higher, } \\
\Pi_{\mathrm{S}}^{\mathrm{MR}-\mathrm{C}}>\Pi_{\mathrm{S}}^{\mathrm{MT}-\mathrm{C}}>\Pi_{\mathrm{S}}^{\mathrm{NC}}, & \text { if } \varsigma \text { is relatively low. }
\end{array}
$$

From the perspective of the entire CLSC system, we can see that the profit of CLSC is the lowest in the NC mode. According to the previous conclusions, the green manufacturing innovation level, market demand, and collection rate are the lowest but the price is higher than the other two modes under noncooperation scenario; thus, the performance is naturally the worst. However, it is unexpected to notice that the CLSC system's profit in the MT-C mode is maximum when $\zeta$ is higher. The previous propositions clearly show that the equilibrium strategies in the MR-C mode are optimal; hence, the relationship of total profits should be always described as $\Pi_{\mathrm{S}}^{\mathrm{MR}-\mathrm{C}}>\Pi_{\mathrm{S}}^{\mathrm{MT}-\mathrm{C}}>\Pi_{\mathrm{S}}^{\mathrm{NC}}$; this seems more reasonable. Nevertheless, some situations should be taken into consideration, for instance, the thirdservice provider's income only comes from collecting used products, and the benefit of collection activity is relatively low. Therefore, although the MR-C mode enjoys optimal decision variable values, the impact on the increase of thirdservice provider's revenue is limited, as shown in Figure 8; compared with the retailer's profit, the third-service provider contributes very little to the CLSC system, this leads to a relative low profit of the MR-C mode ultimately. In MT-C scenario, the retailer as the Stackellberg follower makes decisions individually, which can obtain more profit through retail business in comparison to the third-service provider in MR-C mode; thus, the retailer's contribution to the CLSC system is a lot higher. Furthermore, as stated in previous 


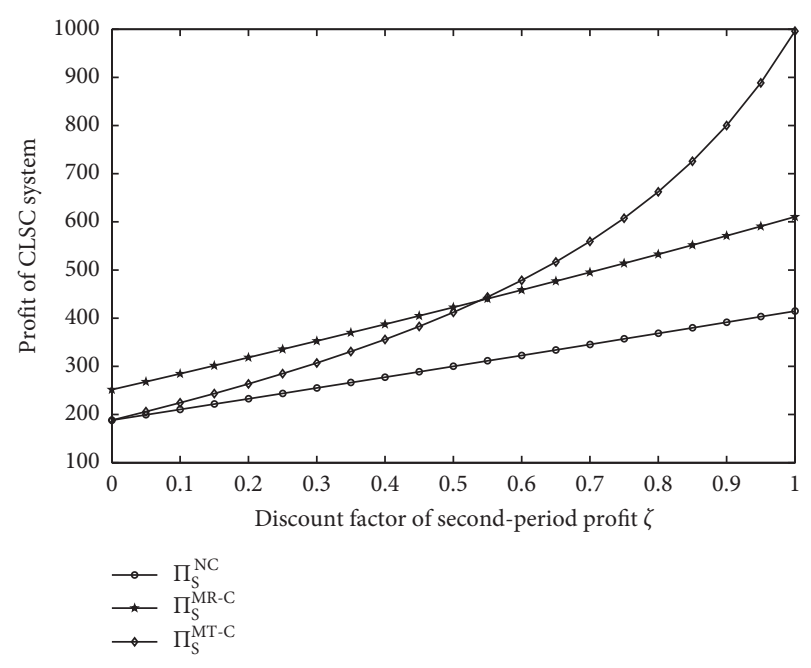

FIgURE 9: Analysis of total profit.

conclusions, the profit of cooperative organization in the MT-C mode is at an intermediate level, so it is a reasonable result that the total profit of the CLSC system is maximum in the MT-C mode.

However, when $\zeta$ is lower, this implies that the profit of period 2 will decrease significantly compared to period 1. More specifically, a lower $\zeta$ will cause a substantial drop in retailer's profit of the $\mathrm{MT}-\mathrm{C}$ mode, which reduces the total profit of MT-C mode obviously, and finally, the order will be changed as follows $\Pi_{\mathrm{S}}^{\mathrm{MR}-\mathrm{C}}>\Pi_{\mathrm{S}}^{\mathrm{MT}-\mathrm{C}}>\Pi_{\mathrm{S}}^{\mathrm{NC}}$. Therefore, from the perspective of CLSC system's total profit, there is no single optimal mode; it varies with the value of $\zeta$ instead. It is important to note that we only analyze the decision-making of decentralized CLSC and the manufacturer is the Stackelberg leader; hence, the primary goal is to determine which CLSC member to cooperate with can maximize its profit. As can be seen from the previous conclusion, the profit of cooperative organization is maximum in the MR- $\mathrm{C}$ mode; this implies that the manufacturer can get more from it, and the next problem to be solved is the profit distribution with retailer. From this point of view, the retailer is the best partner for the manufacturer, that is, the MR-C mode is the most beneficial to the manufacturer.

\section{Conclusions}

In this paper, we investigate a two-period CLSC in which the green manufacturing innovation is taken into consideration, and the manufacturer is willing to cooperate with CLSC members. The equilibrium strategies are obtained by establishing Stackelberg game models of three cooperationrelated modes, namely, NC mode, MR-C mode, and MT-C mode. The main contributions of this paper to the theoretical research of CLSC are as follows. A comprehensive study of a two-period dynamic CLSC is carried out, which takes the green manufacturing innovation of the manufacturer and cooperation between members into consideration, and a coordination mechanism is designed. Besides, through the analysis of theoretical models, the optimal cooperation mode is obtained. This is very rare in the existing literature. In addition, this paper also provides practical management suggestions for the actual decision-making of the manufacturer, retailer, third-service provider, and government. The management inspirations are as follows.

Firstly, the manufacturer should primarily take production cost into consideration when making wholesale price decision. In the process of determining the green manufacturing innovation level, comprehensive consideration should be given to the manufacturing expense, the difficulty of green manufacturing, the consumers' preference for green products, and the potential market demand. This can be attributed to the importance of green manufacturing strategy for the manufacturer, thus various factors should be considered before making a decision. If the manufacturer prefers to collaborate with CLSC members on green manufacturing, the retailer is the recommended partner, i.e., the MR-C mode, due to the lowest price, the highest green manufacturing level, and a medium collection rate of this mode. In actual cooperation, the retailer can take advantage of proximity to the market to investigate consumers' preferences for green products and potential market demand and then share this information with the manufacturer. In a word, the manufacturer and retailer make decisions jointly and achieve the goal of maximizing the benefit of cooperative organization. Besides, in order to improve the profit of the cooperative organization and the operational efficiency of the entire CLSC, without prejudice to the interests of other members, the cooperative organization should proactively propose a coordination mechanism to reduce the inefficiency caused by the double marginalization.

Secondly, in the process of determining the retail price, the retailer should mainly take the cost of production, wholesale price, consumers' preferences for green products, and potential market demand into account. The retailer should actively cooperate with the manufacturer on green manufacturing at the same time.

Thirdly, the third-service provider should also consider the prices and potential demand of products when setting the target collection level. This is because high prices will reduce the total demand, and then a reduction in the amount of used products occurs eventually. Moreover, the thirdservice provider should actively respond to the coordination contract proposed by the cooperative organization if its own interests will not be affected, which is conducive to the performance improvement of CLSC.

Finally, government should encourage enterprises to cooperate on green manufacturing innovation and strengthen supervision of the manufacturer and force the manufacturer to be responsible for the entire life cycle of its products and fulfill its social responsibilities. Due to consumers' sensitivity to green products and recycling has a positive impact on the operation efficiency of CLSC, therefore, it is necessary for the government to advocate green consumption and enhance consumers' ecofriendly awareness. However, in developing countries such as China, many factors lead to recycling in the initial stage; hence, the government also needs to provide subsidies to reduce the economic burden of enterprises to implement CLSC 
management, which will make a greater contribution to environmental protection and resource recycling as well.

Although our research is well supported by the previous literature, some limitations still exist, such as only full cooperation and information symmetry are considered. The coordination mechanism designed in this paper is relatively simple; a multiwin situation is not achieved because the profit of the third-service provider remains unchanged. Therefore, a coordination mechanism capable of achieving multiwin situation should be proposed in further studies. The impact of proximity dimensions between partners on cooperation dynamics, the profit distribution of members of cooperative organization, and decisions in asymmetric information situation are also the directions of future research.

\section{Data Availability}

The data used to support the findings of this study are included within this article.

\section{Conflicts of Interest}

The author declares no conflicts of interest.

\section{Acknowledgments}

The author is grateful to the scholars who have contributed to this field of study. This research was supported by the General Foundation of Chongqing Industry Polytechnic College (no. GZY201734-YB).

\section{References}

[1] W. Wang, J. Ding, and H. Sun, "Reward-penalty mechanism for a two-period closed-loop supply chain," Journal of Cleaner Production, vol. 203, pp. 898-917, 2018.

[2] T. Choi, "Environmental impact of voluntary extended producer responsibility: the case of carpet recycling," Resources, Conservation and Recycling, vol. 127, pp. 76-84, 2017.

[3] B. Peng, Y. Tu, E. Elahi, and G. Wei, "Extended producer responsibility and corporate performance: effects of environmental regulation and environmental strategy," Journal of Environmental Management, vol. 218, pp. 181-189, 2018.

[4] H. Wang, Y. Gu, L. Li, T. Liu, Y. Wu, and T. Zuo, "Operating models and development trends in the extended producer responsibility system for waste electrical and electronic equipment," Resources, Conservation and Recycling, vol. 127, pp. 159-167, 2017.

[5] F. Corsini, F. Rizzi, and M. Frey, "Extended producer responsibility: the impact of organizational dimensions on WEEE collection from households," Waste Management, vol. 59, pp. 23-29, 2017.

[6] D. Dempsey, State E-Waste Laws Successful, but May be Challenged, Scientific American Online, New York, NY, USA, 2010.

[7] T. S. Genc and P. D. Giovanni, "Trade-in and save: a twoperiod closed-loop supply chain game with price and technology dependent returns," International Journal of Production Economics, vol. 183, pp. 514-527, 2017.

[8] M. Reimann, Y. Xiong, and Y. Zhou, "Managing a closed-loop supply chain with process innovation for remanufacturing,"
European Journal of Operational Research, vol. 276, no. 2, pp. 510-518, 2019.

[9] W. B. Arfi, L. Hikkerova, and J.-M. Sahut, "External knowledge sources, green innovation and performance," Technological Forecasting \& Social Change, vol. 129, pp. 210-220, 2018.

[10] Z. Liu, K. W. Li, B.-Y. Li, J. Huang, and J. Tang, "Impact of product-design strategies on the operations of a closed-loop supply chain," Transportation Research Part E: Logistics and Transportation Review, vol. 124, pp. 75-91, 2019.

[11] R. Dai, J. Zhang, and W. Tang, "Cartelization or cost-sharing? Comparison of cooperation modes in a green supply chain," Journal of Cleaner Production, vol. 156, pp. 159-173, 2017.

[12] J. L. Wadin, K. Ahlgren, and L. Bengtsson, "Joint business model innovation for sustainable transformation of industries-a large multinational utility in alliance with a small solar energy company," Journal of Cleaner Production, vol. 160, pp. 139-150, 2017.

[13] S. Elia, A. Messeni Petruzzelli, and L. Piscitello, "The impact of cultural diversity on innovation performance of MNC subsidiaries in strategic alliances," Journal of Business Research, vol. 98, pp. 204-213, 2019.

[14] R. C. Savaskan, S. Bhattacharya, and L. N. Van Wassenhove, "Closed-loop supply chain models with product remanufacturing," Management Science, vol. 50, no. 2, pp. 239-252, 2004.

[15] R. C. Savaskan and L. N. Van Wassenhove, "Reverse channel design: the case of competing retailers," Management Science, vol. 52, no. 1, pp. 1-14, 2006.

[16] M. Huang, M. Song, L. H. Lee, and W. K. Ching, "Analysis for strategy of closed-loop supply chain with dual recycling channel," International Journal of Production Economics, vol. 144, no. 2, pp. 510-520, 2013.

[17] X. Hong, Z. Wang, D. Wang, and H. Zhang, "Decision models of closed-loop supply chain with remanufacturing under hybrid dual-channel collection," The International Journal of Advanced Manufacturing Technology, vol. 68, no. 5-8, pp. 1851-1865, 2013.

[18] L. Liu, Z. Wang, L. Xu, X. Hong, and K. Govindan, "Collection effort and reverse channel choices in a closed-loop supply chain," Journal of Cleaner Production, vol. 144, pp. 492-500, 2017.

[19] Y. Huang, "A closed-loop supply chain with trade-in strategy under retail competition," Mathematical Problems in Engineering, vol. 2018, Article ID 1510959, 16 pages, 2018.

[20] J. Gao, H. Han, L. Hou, and H. Wang, "Pricing and effort decisions in a closed-loop supply chain under different channel power structures," Journal of Cleaner Production, vol. 112, pp. 2043-2057, 2016.

[21] X. Gu, P. Ieromonachou, L. Zhou, and M.-L. Tseng, "Developing pricing strategy to optimise total profits in an electric vehicle battery closed loop supply chain," Journal of Cleaner Production, vol. 203, pp. 376-385, 2018.

[22] P. Zhang, Y. Xiong, Z. Xiong, and W. Yan, "Designing contracts for a closed-loop supply chain under information asymmetry," Operations Research Letters, vol. 42, no. 2, pp. 150-155, 2014.

[23] P. Hasanov, M. Y. Jaber, and N. Tahirov, "Four-level closed loop supply chain with remanufacturing," Applied Mathematical Modelling, vol. 66, pp. 141-155, 2019.

[24] Q. He, N. Wang, Z. Yang, Z. He, and B. Jiang, "Competitive collection under channel inconvenience in closed-loop supply chain," European Journal of Operational Research, vol. 275, no. 1, pp. 155-166, 2019. 
[25] P. D. Giovanni and G. Zaccour, "A two-period game of a closed-loop supply chain," European Journal of Operational Research, vol. 232, no. 1, pp. 22-40, 2014.

[26] T. S. Genc and P. D. Giovanni, "Closed-loop supply chain games with innovation-led lean programs and sustainability," International Journal of Production Economics, vol. 219, pp. 440-456, 2020.

[27] L. Xu and C. Wang, "Sustainable manufacturing in a closedloop supply chain considering emission reduction and remanufacturing," Resources, Conservation and Recycling, vol. 131, pp. 297-304, 2018.

[28] A. Cherrafi, J. A. Garza-Reyes, V. Kumar, N. Mishra, A. Ghobadian, and S. Elfezazi, "Lean, green practices and process innovation: a model for green supply chain performance," International Journal of Production Economics, vol. 206, pp. 79-92, 2018

[29] D. M. Yazan, V. Albino, and A. Messeni Petruzzelli, "Analyzing the environmental impact of transportation in reengineered supply chains: a case study from a leather upholstery company," Transportation Research Part D: Transport and Environment, vol. 16, no. 4, pp. 335-340, 2011.

[30] D. M. Yazan, A. C. Garavelli, A. Messeni Petruzzelli, and V. Albino, "The effect of spatial variables on the economic and environmental performance of bioenergy production chains," International Journal of Production Economics, vol. 131, no. 1, pp. 224-233, 2011.

[31] A. Messeni Petruzzelli, R. Maria Dangelico, D. Rotolo, and V. Albino, "Organizational factors and technological features in the development of green innovations: evidence from patent analysis," Innovation, vol. 13, no. 3, pp. 291-310, 2011.

[32] L. Ardito, A. Messeni Petruzzelli, and V. Albino, "Investigating the antecedents of general purpose technologies: a patent perspective in the green energy field," Journal of Engineering and Technology Management, vol. 39, pp. 81-100, 2016.

[33] L. Ardito, A. M. Petruzzelli, and C. Ghisetti, "The impact of public research on the technological development of industry in the green energy field," Technological Forecasting and Social Change, vol. 144, pp. 25-35, 2019.

[34] L. Zhang, L. Xue, and Y. Zhou, "How do low-carbon policies promote green diffusion among alliance-based firms in China? An evolutionary-game model of complex networks," Journal of Cleaner Production, vol. 210, pp. 518-529, 2019.

[35] C. Doblinger, K. Surana, and L. D. Anadon, "Governments as partners: the role of alliances in US cleantech startup innovation," Research Policy, vol. 48, no. 6, pp. 1458-1475, 2019.

[36] D. Ghosh and J. Shah, "A comparative analysis of greening policies across supply chain structures," International Journal of Production Economics, vol. 135, no. 2, pp. 568-583, 2012.

[37] A. Capaldo and A. M. Petruzzelli, "Partner geographic and organizational proximity and the innovative performance of knowledge-creating alliances," European Management Review, vol. 11, no. 1, pp. 63-84, 2014.

[38] A. Capaldo and A. Messeni Petruzzelli, "Origins of knowledge and innovation in R\&D alliances: a contingency approach," Technology Analysis \& Strategic Management, vol. 27, no. 4, pp. 461-483, 2015.

[39] L. Ardito, A. Messeni Petruzzelli, F. Peruffo, and E. Pascucci, "Inter-firm R\&D collaborations and green innovation value: the role of family firms' involvement and the moderating effects of proximity dimensions," Business Strategy and the Environment, vol. 28, no. 1, pp. 185-197, 2019. 